Research article

urn:1sid:zoobank.org:pub:256407D2-64CC-4B3C-8C24-FA7C8CBF50B2

\title{
The Chimarra lehibemavo species-group, new and endemic to Madagascar (Trichoptera, Philopotamidae)
}

\author{
François-Marie GIBON \\ IRD, Centre de Biologie pour la Gestion des Populations (UMR INRA / IRD / CIRAD / \\ Montpellier Supagro), Campus de Baillarguet, CS 30016, 34988 Montferrier sur Lez Cedex, France. \\ E-mail : Francois-Marie.Gibon@ird.fr \\ urn:Isid:zoobank.org:author:C68C830F-626B-42E5-91EC-8147C42E8B03
}

\begin{abstract}
The Chimarra lehibemavo group is described to include thirteen new species: Chimarra lehibemavo sp. nov., C. cebegepi sp. nov., C. fenoevo sp. nov., C. forcellinii sp. nov., C. fotobohitra sp. nov., C. gattolliati sp. nov., C. gensonae sp. nov., C. jejyorum sp. nov., C. hamatra sp. nov., C. makiorum sp. nov., C. moramanga sp. nov., C. saha sp. nov. and C. tamara sp. nov. The adults are easily recognizable by their large size, yellow colour and the structure of the male genitalia. The membranous tergum IX and the absence of the mesal lobe of tergum X are observed in other lineages, but the strong asymmetrical deformation of the phallotheca is apomorphic. The group is monophyletic with unknown affinities, but a preliminary phylogenetic placement is suggested following genetic analysis of two specimens. With one exception, the species have restricted geographical distributions in Madagascar and inhabit rivers in eastern pristine rainforests.
\end{abstract}

Keywords. Caddisflies, Chimarrinae, new species, biogeography, systematics.

Gibon F.-M. 2017. The Chimarra lehibemavo species-group, new and endemic to Madagascar (Trichoptera, Philopotamidae). European Journal of Taxonomy 319: 1-31. https://doi.org/10.5852/ejt.2017.319

\section{Introduction}

The genus Chimarra Stephens, 1829 is the largest genus in the Trichoptera (Morse 2015). It is almost cosmopolitan in distribution, only absent from the southernmost areas of South America, New Zealand and many oceanic islands. The Neotropical and Oriental regions harbour the main known diversity. For a long time ignored, the rich Malagasy fauna of Chimarra begins to be studied. Ten species are reported to date from the island, but already collected material has permitted to estimate a richness exceeding sixty species (Gibon et al. 1999). The morphological diversity offered by this material has revealed the presence of distinct lineages and this was confirmed by the DNA-based phylogenies published by Wahlberg \& Johanson (2014) and Kjer et al. (2014).

The long-term objective of our studies was to contribute to the conservation of the Malagasy fauna, not only for emblematic, economic or with high touristic value species, but also taking into account little known taxa important for ecosystem functioning. For this purpose, history of settlement, endemism, 
vicariance and redundancy are key data, these studies are much more informative at infrageneric levels (Resh \& Unzicker 1975).

The genus Chimarra is monophyletic and clearly characterized by morphological synapomorphies. Three of the four recognized subgenera are reported only from the New World (mainly the northern part of South America and the Antilles). All the Old World species belong to the nominal subgenus Chimarra, which secondarily invaded North America (Ross 1956; Blahnik 1998), an event dated by Wahlberg \& Johanson (2014). A few large lineages were considered by Ross (1956) and redescribed by Blahnik et al. $(2009,2012)$. These lineages illustrate the long-term history of the genus. The species group defined here should be included, thereafter, in the great historical lineages, that would require other approaches such as molecular studies or larval morphology.

I have recently described two species belonging to the minima species group and widely distributed in the open lowland landscapes of Madagascar (Gibon 2015). By contrast, the lehibemavo group includes numerous species which are, with the exception of Chimarra fenoevo sp. nov., restricted to the pristine rainforests and microendemic (sensu Gibon 2000 and Wilmé et al. 2006). The monophyly of the group is inferred from male genital structure, which includes an unique combination of characters and a remarkable apomorphy. No closely relative group could be identified.

\section{Material and methods}

The material was collected during the project "Biodiversité et Biotypologie des eaux continentales malgaches" jointly conducted by the ORSTOM and the CNRE (Antananarivo). The equipment, the sampling method and the study areas were described by Elouard \& Gibon (2001). Unless otherwise stated, the material was collected by the author. Some field campaigns benefited from the logistic of the WWF; in those cases, the main results and detailed ecological descriptions of the regions were published (Andringitra: Goodman 1996; Andohahela: Goodman 1999; Marojejy: Goodman 2000). Specimens were captured using a portable light trap, which was composed of a black light and a gas lamp, and subsequently preserved in $75 \%$ ethanol. The male genitalia of some specimens were cleared in a solution of potassium hydroxide, studied under the microscope in cedar oil, and mounted on slides in Euparal ${ }^{\circledR}$. The holotypes, paratypes and other specimens are deposited in the CBGP (Montferrier).

The storage in ethanol $(75 \%)$ at room temperature is not favourable to the long-term preservation of the DNA (K. Kjer, personal communication during the $\mathrm{XV}^{\text {th }}$ International Symposium on Trichoptera), our colleague Gwenaelle Genson (INRA/CBGP) managed to obtain sequences from two specimens. The extraction of genomic DNA was performed on whole specimens, using "DNeasy 96 Blood \& Tissue extraction (QIAGEN)", following standard protocol. A primer cocktail described by Cruaud et al. (2010) was used to sequence the standard bar-code sequence of the mitochondrial COI gene (cytochrome $\mathrm{c}$ oxidase I). Voucher sequenced specimens and their DNA are deposited in the collections of the CBGP.

The terminology used thereafter is that of Blahnik (1998). Schematic ecological profiles of the capture sites were established according to altitude, distance to the source and watershed, their construction, use and limitations were described and discussed by Randriamasimanana \& Gibon (2001).

\section{Acronyms}

$\begin{array}{ll}\text { CBGP } & =\text { Centre de Biologie pour la Gestion des Populations (Montferrier, France) } \\ \text { CNRE } & =\text { Centre National de Recherche sur l'Environnement (Antananarivo, Madagascar) } \\ \text { INRA } & =\text { Institut National de la Recherche Agronomique (Paris, France) } \\ \text { ORSTOM } & \text { Office de la Recherche Scientifique et Technique Outre-Mer (Paris, France) } \\ \text { WWF } & =\text { World Wide Fund for Nature (Gland, Switzerland) }\end{array}$




\title{
Results
}

\section{Taxonomy}

\author{
Class Insecta Linnaeus, 1758 \\ Order Trichoptera Kirby, 1813 \\ Superfamily Philopotamoidea Stephens, 1829 \\ Family Philopotamidae Stephens, 1829 \\ Subfamily Chimarrinae Rambur, 1842 \\ Genus Chimarra Stephens, 1829 \\ Subgenus Chimarra Stephens, 1829 \\ The Chimarra lehibemavo group
}

\section{Diagnosis}

All the Old World species of the genus belong to the nominal sub-genus Chimarra Stephens, 1829, characterized by a curvature of the stem of Rs vein in the forewing. In some groups, as minuta and georgensis, this curvature is weakly marked. In the lehibemavo group, the stem of Rs vein is not curved but clearly angular (Fig. 1). This constitutes an accentuated state of the character. The lehibemavo group differs from the large digitata lineage by the absence of the median lobe of tergum $\mathrm{X}$ and the membranous tergum IX; it differs from the tsudai lineage by the undivided lateral lobes of tergum X. These lateral lobes are U-shaped or boomerang-shaped with one dorso-distal and one ventral branch. This is also observed in the georgensis species group but species of this latter group have a dorsally membranous tergum $\mathrm{X}$ and a reduced but sclerotized tergum IX. Above all, the phallic apparatus is the best characteristic of the group: the phallotheca is laterally split in two plates (thereafter named dorsal and ventral lamina); each of these plates is distorted in its own way, making the apparatus asymmetric. This phallotheca, associated with a variable internal sclerite and a large phallotremal sclerite, is a remarkable apomorphic character, the best way to identify the group. Each species exhibits specific forms of phallotheca and phallic sclerites, making the phallic apparatus the best diagnostic character.

In Madagascar, alive adults of the group are easily identifiable by the combination of the yellow colour and the large size. Most of the Malagasy Chimarra are black or brown, but the species of the minima and dybowskina groups are yellow or pale brown; the forewing length varies from 4 to $6 \mathrm{~mm}$. In Africa, some species from mountain areas are quite large (for exemple $6.2 \mathrm{~mm}$ in Chimarra philipponi Gibon, 1986 from Guinea or $7.0 \mathrm{~mm}$ in Chimarra calidopectoris Wahlberg et al., 2014 from Malawi). The

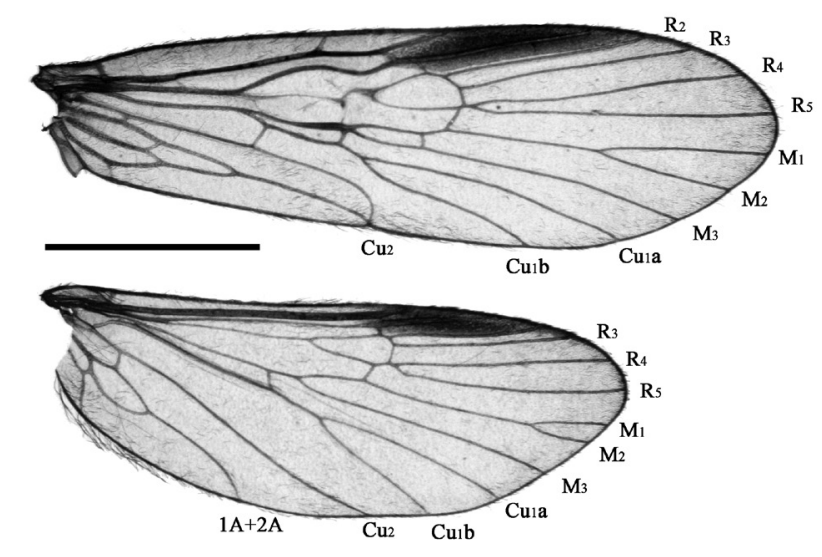

Fig. 1. Chimarra jejyorum sp. nov., right wings. Scale bar $=2 \mathrm{~mm}$. 
lehibemavo group is a little bigger with a range of $5.5-10 \mathrm{~mm}$ - forewing length - and a median value of $7.3 \mathrm{~mm}$.

\section{Description}

Adult

Three ocelli. Labial palps 3-segmented. Maxillary palps 5-segmented, first segment short, second with an apical tuft of setae. Spur formula: 1/4/4. Forewing with forks 1, 2, 3 and 5; stem of R1 sinuous; stem of Rs with an angular bend a little before discoidal cell, node thickened at discal cell; $\mathrm{M}$ vein 3-branched (M4 absent), $\mathrm{M}_{1+2}$ long petiolate. Hind wing with forks 1,2, 3 and 5; $1 \mathrm{~A}$ and 2A join to form a loop and reach together wing margin.

Abdominal segment VIII complete, smaller than the VII, sternite VIII with a ventral keel. Sternite IX with a ventral keel and large antero-lateral lobes deeply invaginated in sternite VIII; in lateral view: latero-distal margin convex, sub triangular or rounded. Tergite IX membranous. Tergum X completely divided in two lateral lobes, median part membranous without noticeable median lobe. When viewed laterally, each lateral lobes v- or boomerang-shaped with one dorsal and one ventral branch. Preanal appendages small, simple and generally knoblike. Inferior appendages one-segmented, shape and size variable depending on the species; when viewed laterally, rectangular or triangular with small lobes along the caudal margin, most species having an additional lobe on the inner side (internal lobe, Fig. 4A, C). Phallic apparatus comparatively large, comprising a bulbous base prolonged by a tubular phallotheca (structure sometimes described as pistol-shaped), remarkably long (longer than abdominal segments VIII, IX and X). Phallotheca sclerotized, distal part split, forming two conspicuous, asymmetrically enlarged or distorted extensions (dorsal and ventral lamina, Fig. 2D-E). Endotheca with: (1) a well developed phallotremal sclerite complex, (2) a large, variable in shape, internal sclerite, usually spiniform but sometimes globular or bullet-shaped.

\section{Biomolecular data}

The CO1 barcoding sequence is known for two specimens only, one male of $C$. fenoevo sp. nov. and one male of $C$. tamara sp. nov. The identification research in the database BOLD (Ratnasingham \& Hebert 2007) indicates for $C$. fenoevo sp. nov. a similarity percentage of 95.54 with $C$. OF sp. MG9, an unidentified Malagasy species included in the phylogeny published by Kjer et al. (2014, supplementary material). For $C$. tamara sp. nov., the maximum percentage is only 83.31, but again with $C$. OF sp. MG9. In the electronic supplement file of Kjer et al. (2014), the nearest relative of $C$. OF sp. MG9 (in a COI based phylogeny) is C. orumbera Cartwright, 2002 from Australia. Chimarra orumbera is easily distinguished from any species of the lehibemavo group by the presence of the dorsal lobe of tergum $\mathrm{X}$ (although quite simple and poorly sclerotized), and the absence of distortion of the phallotheca. These data will be more useful for future study, when the afrotropical fauna will be better known. For the moment, I would not say that this preliminary result confirms or, at least, does not refute the conclusion of the morphological study: the lehibemavo group is not close to any other among the afrotropical species.

Chimarra lehibemavo sp. nov. urn:1sid:zoobank.org:act:419A1C29-F941-42A7-9663-4FE9CBCF186B Figs 2, 16

\section{Diagnosis}

Chimarra lehibemavo sp. nov. is one of the largest Afrotropical species of the genus. Together with C. cebegepi sp. nov. and C. saha sp. nov. it forms a sub-group being characteristic in having a long and finger-shaped dorsal branch of tergum X (Fig. 2A1, B1) and a long dorsal branch of the inferior appendage (Fig. 2A, C3). Chimarra lehibemavo sp. nov. is characterized by the phallic internal sclerite 
which is stout and shorter than the phallotremal sclerite, whereas longer in Chimarra cebegepi sp. nov. (Fig. 3D-E) and Chimarra saha sp. nov. (Fig. 13D-E).

\section{Etymology}

From the Malagasy 'lehibe' ( = big) and 'mavo' (= yellow), referring to the colour and large size of the species.

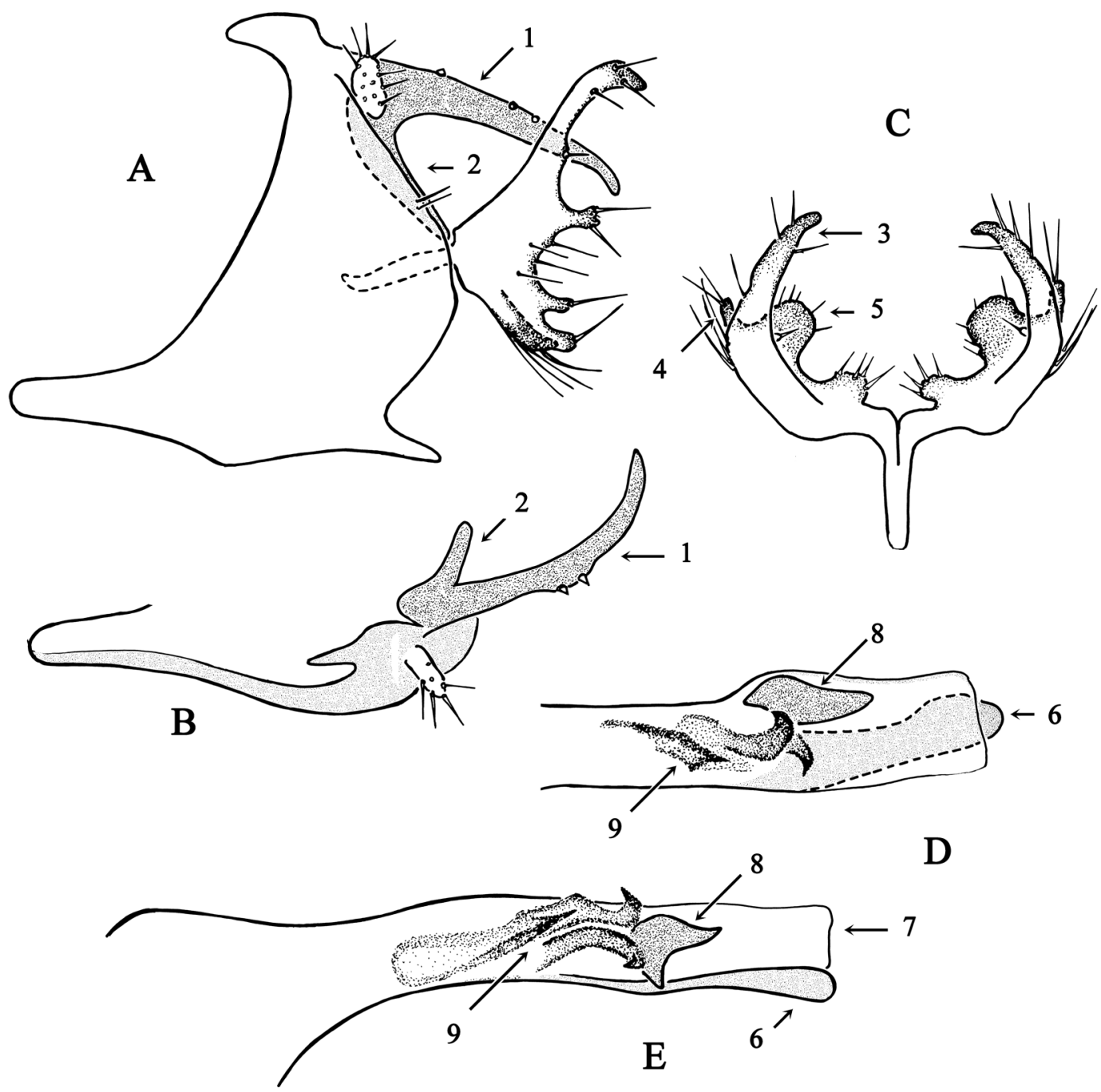

Fig. 2. Chimarra lehibemavo sp. nov. A-B. Abdominal segments IX and X. A. Lateral view. B. Dorsal view (partim). C. Inferior appendage, dorsal view. D-E. Phallic apparatus. D. Dorsal view. E. Lateral view. $1=$ Lateral lobe of tergum X, dorsal branch. $2=$ Lateral lobe of tergum X, ventral branch. $3=$ Inferior appendage, dorsal branch. $4=$ Inferior appendage, ventral branch. $5=$ Inferior appendage, internal lobe. $6=$ Phallotheca, ventral lamina. $7=$ Phallotheca, dorsal lamina. $8=$ Phallotheca, internal sclerite. $9=$ Phallotheca, phallotremal sclerite. Scale bar $=0.5 \mathrm{~mm}$. 


\section{Type material}

\section{Holotype}

MADAGASCAR: $\widehat{\gamma}$, mounted on 3 slides, remaining parts in alcohol, Andranomifitatra River, camp

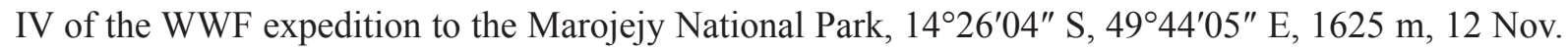
1996, leg. D. Randriamasimanana and J. Legrand.

\section{Paratypes}

MADAGASCAR: 10 , in alcohol, Andranomifitatra River, camp III of the WWF expedition to the Marojejy National Park, $14^{\circ} 26^{\prime} 02^{\prime \prime}$ S, 49 $44^{\prime} 05^{\prime \prime}$ E, 1225 m, 25 Oct. 1996, leg. D. Randriamasimanana and J. Legrand; $3 \hat{\partial}$, in alcohol, camp II of the WWF expedition to the Marojejy National Park,

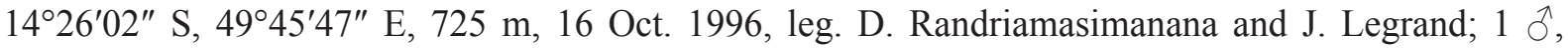
mounted on 3 slides, remaining parts in alcohol, camp II of the WWF expedition to the Marojejy National

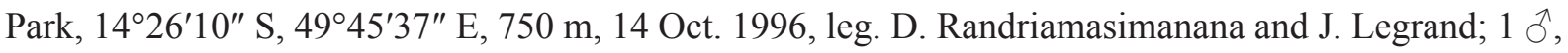
mounted on 2 slides, remaining parts in alcohol, camp I of the WWF expedition to the Marojejy National Park, 14²5'50" S, 4946'18" E, 500 m, 12 Oct. 1996, leg. D. Randriamasimanana and J. Legrand.

\section{Description}

SIZE. Forewing $10.0 \mathrm{~mm}$, hind wing $8.0 \mathrm{~mm}$.

TERgum X. Lateral lobes deeply divided, boomerang-shaped with long dorsal and ventral branches (Fig. 2A).

INFERIOR APPENDAGES. Roughly triangular, anterior margin length about twice the ventral margin length; hypotenuse sinuous; internal lobe small and thumb-shaped on lateral view, wide and sinuous on dorsal view.

Phallic APparatus. Little modified, ventral lamina separate and forming long digitiform plate (Fig. 2C-D), dorsal lamina wide and sub rectangular; internal sclerite short and stout, bifid lateral view; phallotremal sclerite with one central peaked element and two hook-shaped lateral elements.

\section{Distribution}

Madagascar (endemic), Marojejy National Park.

Chimarra cebegepi sp. nov. urn:1sid:zoobank.org:act:F5486868-6EBC-46F2-97C8-9AE3A893C8B7

Figs 3,17

\section{Diagnosis}

Together with C. lehibemavo sp. nov. and C. saha sp. nov., Chimarra cebegepi sp. nov. forms a subgroup of three closely related species. C. lehibemavo sp. nov. is characterized by the short internal sclerite of the phallic apparatus (Fig. 2D-E), this latter is long and apically curved in the other two species. C. cebegepi sp. nov. differs from C. saha sp. nov. by the distal margin of the inferior appendage slightly concave and regularly rounded in lateral view (Fig. 3A). Moreover C. saha sp. nov. is characterized by the lateral deflection of the dorsal lamina of the phallotheca (Fig. 13E), which is more developed than in C. cebegepi sp. nov. (Fig. 3E).

\section{Etymology}

The name is designed from the acronym of the Centre de Biologie pour la Gestion des Populations. 


\section{Type material}

\section{Holotype}

MADAGASCAR: $\widehat{\sigma}$, mounted on 7 slides, camp I of the WWF expedition to the Marojejy National Park, 14²6'02" S, 4946'20" E, 450 m, 13 Oct. 1996, leg. D. Randriamasimanana and J. Legrand.

\section{Paratypes}

MADAGASCAR: 1 , mounted on 3 slides, remaining parts in alcohol, camp II of the WWF expedition to the Marojejy National Park, $14^{\circ} 26^{\prime} 10^{\prime \prime}$ S, 49 $45^{\prime} 37^{\prime \prime}$ E, 750 m, 14 Oct. 1996, leg. D. Randriamasimanana and J. Legrand; $6 \widehat{\partial}$, in alcohol, camp I of the WWF expedition to the Marojejy National Park, $14^{\circ} 26^{\prime} 13^{\prime \prime} \mathrm{S}, 49^{\circ} 46^{\prime} 17^{\prime \prime}$ E, 460 m, 12 Oct. 1996, leg. D. Randriamasimanana and J. Legrand.
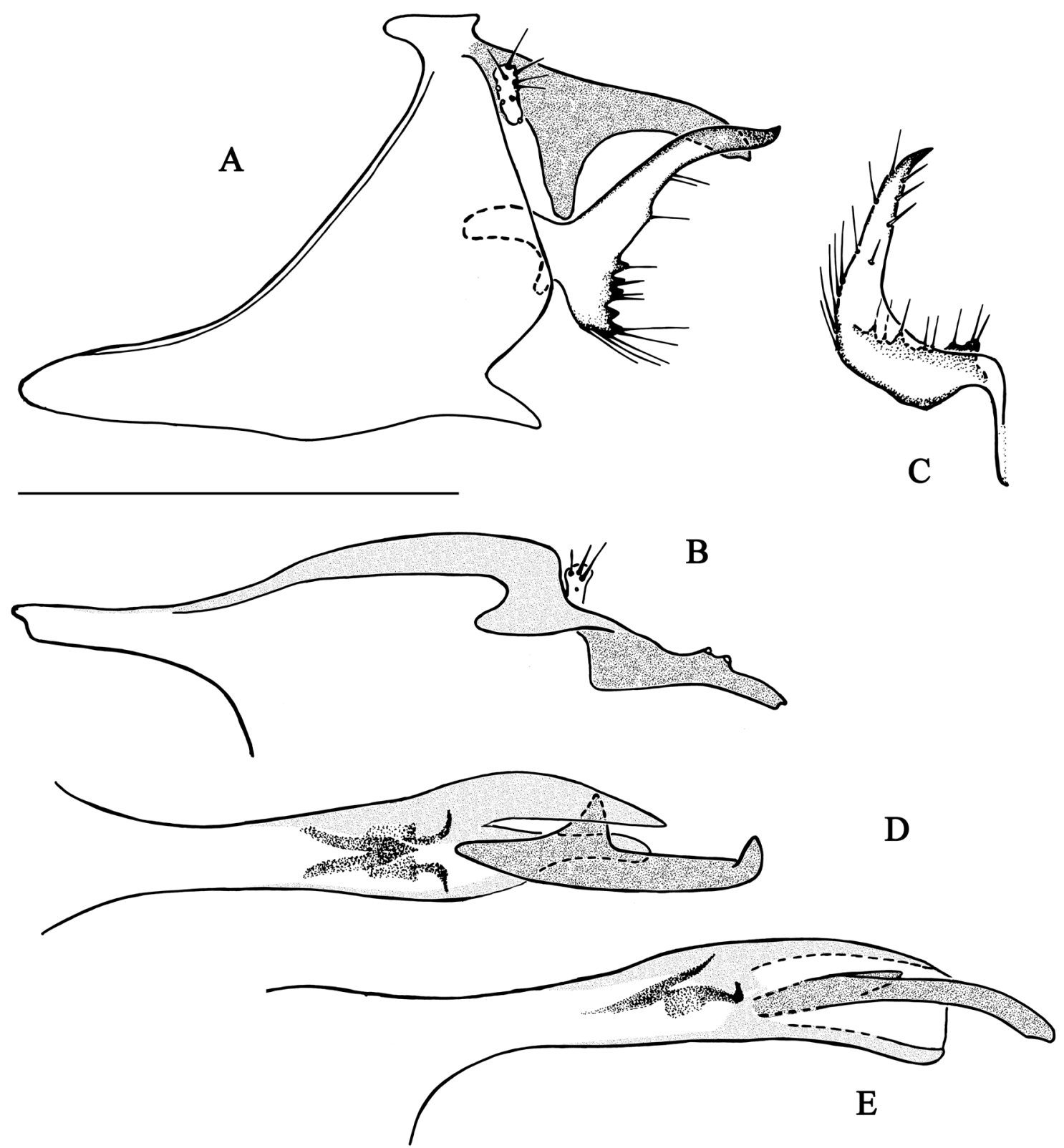

Fig. 3. Chimarra cebegepi sp. nov. A-B. Abdominal segments IX and X. A. Lateral view. B. Dorsal view (partim). C. Inferior appendage, dorsal view. D-E. Phallic apparatus. D. Dorsal view. E. Lateral view. Scale bar $=0.5 \mathrm{~mm}$. 


\title{
Description
}

Size. Forewing $8.5 \mathrm{~mm}$, hind wing $6.8 \mathrm{~mm}$.

Tergum X. Lateral lobes not as deeply divided as in C. lehibemavo sp. nov., dorsal branch longer than ventral one (lateral view).

INFERIOR APPENDAGES. Dorsal branch elongate, regularly narrowing; ventral branch short; internal lobe constituted by six small indentations (Fig. 3C); distal margin concave and regularly rounded in lateral view (Fig. 3A).

Phallic apparatus. Phallotheca split from mid-length in two asymmetrical laminas of equivalent length; internal sclerite long (longer than the laminas of the phallotheca) with curved apex and, before midlength, short and triangular protuberance (Fig. 3D); phallotremal sclerite present with two lateral, hookshaped elements.

\section{Distribution}

Madagascar (endemic), Marojejy National Park.

Chimarra fenoevo sp. nov. urn:1sid:zoobank.org:act:F13971CA-B594-4FDF-9A4D-FB32EDE20E78

\author{
Figs 4, 15
}

\section{Diagnosis}

Chimarra fenoevo sp. nov. is closely related to C. forcellinii sp. nov. These two species are characterized by the curved dorsal branches of tergum X (Figs 4B, 5B). They differ by the shape of the inferior appendages: triangular in C. fenoevo sp. nov. (Fig. 4A), whereas L-shaped in C. forcellinii sp. nov. (Fig. 5A).

\section{Etymology}

The name is that of the nearest city to the type locality.

\section{Type material}

\section{Holotype}

MADAGASCAR: 7 , mounted on 6 slides, tributary of the Manampanihy River near Fenoevo, 2441'00" S, 4653'39" E, 72 m, 15 Apr. 1992, leg. J.-M. Elouard.

\section{Paratypes}

MADAGASCAR: $1 \hat{\partial}$, mounted on 4 slides, same data as holotype; $3 \hat{\partial} \hat{\partial}$, in alcohol, same data as holotype; 3 ठิ $\widehat{\jmath}$, Manambolo River, seven kilometres from Berohanga, $24^{\circ} 35^{\prime} 07^{\prime \prime} \mathrm{S}, 46^{\circ} 35^{\prime} 11^{\prime \prime} \mathrm{E}$, 440 m, 5 Jun. 1994.

\section{Other specimens}

MADAGASCAR: $1 \delta^{\lambda}$, tributary of the Rianila River, road to Lakato, $48^{\circ} 21^{\prime} 50^{\prime \prime} \mathrm{E}, 19^{\circ} 03^{\prime} 30^{\prime \prime} \mathrm{S}$,

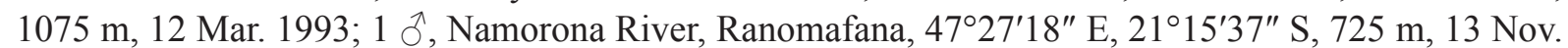

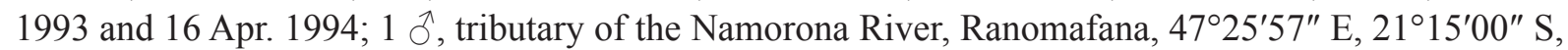

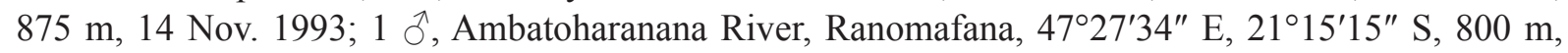

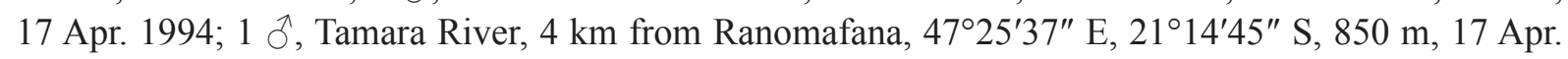

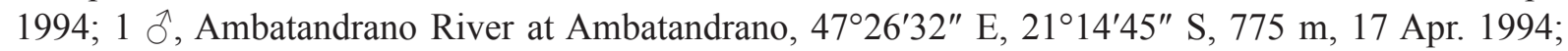
1 oै, tributary of the Namorona River, $47^{\circ} 25^{\prime} 11^{\prime \prime}$ E, $21^{\circ} 15^{\prime} 47^{\prime \prime}$ S, 1225 m, 18 Apr. 1994; 1 ô, tributary 


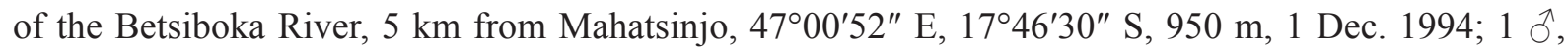

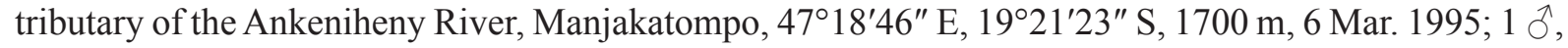

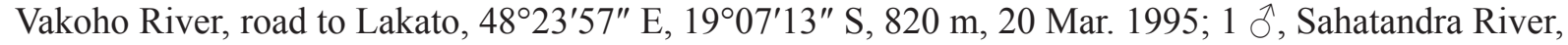

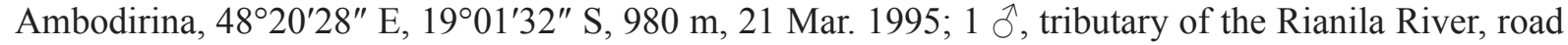

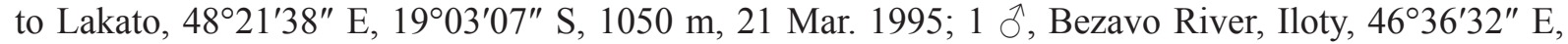

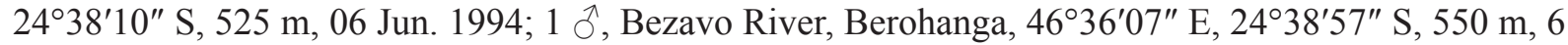

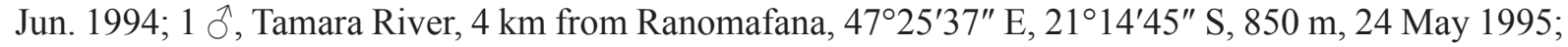

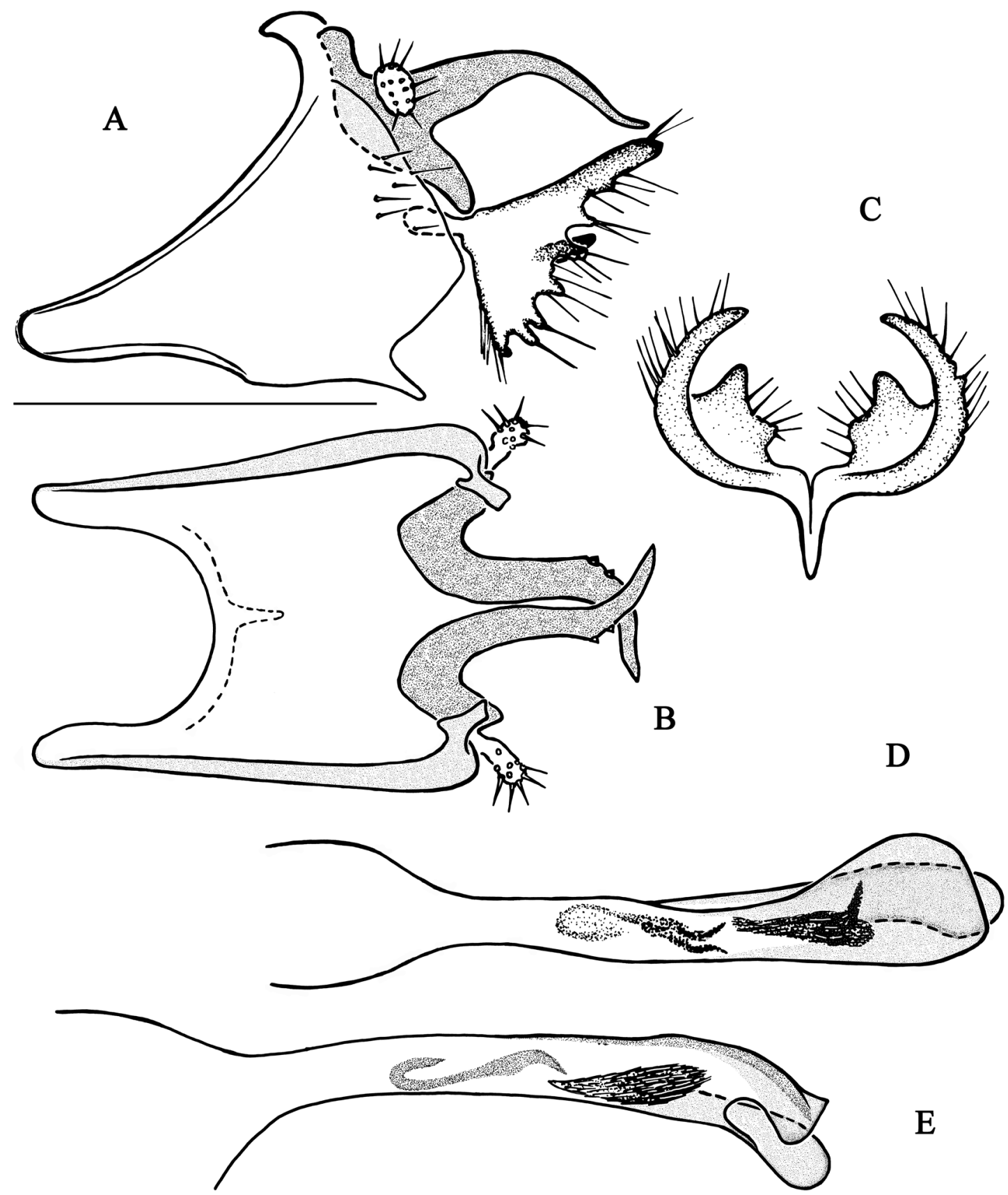

Fig. 4. Chimarra fenoevo sp. nov. A-B. Abdominal segments IX and X. A. Lateral view. B. Dorsal view. C. Inferior appendage, dorsal view. D-E. Phallic apparatus. D. Dorsal view. E. Lateral view. Scale bar = $0.5 \mathrm{~mm}$. 


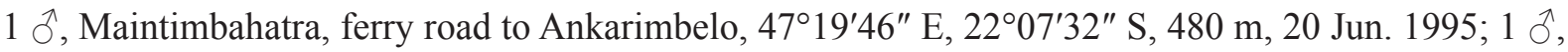
Sakamalio, Andohahela, 4640'56" E, 24³2'07" S, 750 m, 2 Feb. 1996; 1 ○े, Manambaroa River, 24 km

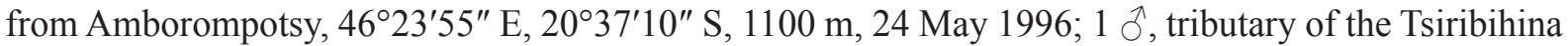

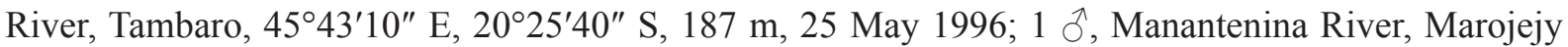

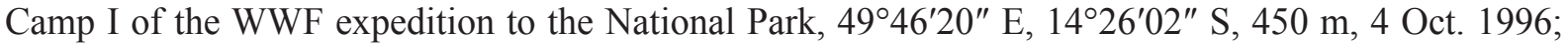

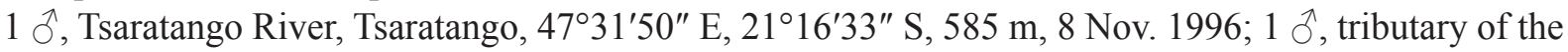

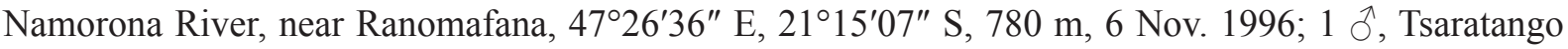

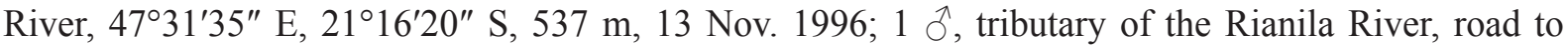

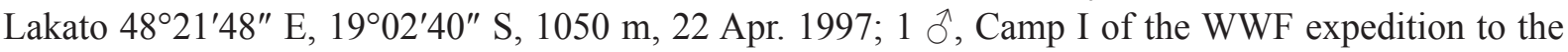
Marojejy National Park, 4946'33" E, 14²6'20" S, 430 m, 17 Oct. 1996.

\section{Description}

SIzE. Forewing $8.3 \mathrm{~mm}$, hind wing $6.6 \mathrm{~mm}$.

TERGUM X. Ventral branch short, directed ventrally; dorsal branch elongated and curved ventrally, apices crossing in dorsal view.

INFERIOR APPENDAGES. Triangular, hypotenuse sinuous, with half a dozen of small lobes (lateral view), internal lobe large, very apparent on the dorsal view (Fig. 4C).

Phallic apPaRatus. Distal part of dorsal lamina widened and rounded, ventral lamina digitiform, slightly longer than dorsal lamina; internal sclerite short with a rough surface and a small lateral extension (Fig. 4D); phallotremal sclerite relatively small and thin.

\section{Distribution}

Madagascar (endemic), quite widely distributed.

Chimarra forcellinii sp. nov. urn:1sid:zoobank.org:act:656986B7-7CBD-45A3-B73D-6C12058B2079

Figs 5,16

\section{Diagnosis}

Chimarra forcellinii sp. nov. is a close relative of $C$. fenoevo sp. nov. These two species differ by the shape of the inferior appendages (lateral view), L-shaped in C. forcellinii sp. nov. (Fig. 5A), whereas triangular in $C$. fenoevo sp. nov. (Fig. 4A). Another useful diagnostic character is the maximum width of the phallotheca: that is at the apex in C. fenoevo sp. nov. (Fig. 4D), whereas in C. forcellinii sp. nov. it is in the middle of the tubular part (Fig. 5D).

\section{Etymology}

This species is dedicated to Maxence Forcellini in tribute to his work for the aquatic biomonitoring of La Réunion.

\section{Type material}

\section{Holotype}

MADAGASCAR: ${ }^{\wedge}$, Sahatandra River near Ambodiriana, 1901'32" S, 48²0'28" E, 980 m, 4 Apr. 1992, leg. J.-M. Elouard.

\section{Description}

Size. Forewing $6.3 \mathrm{~mm}$, hind wing $5.3 \mathrm{~mm}$. 
Tergum X. Both dorsal and ventral branches elongated, ventral branch almost straight, dorsal branch slightly and regularly curved ventrad in lateral view, strongly angled inward in dorsal view (Fig. 5B).

INFERIOR APPENDAGES. L-shaped (lateral view), anterior branch twice as long as ventral one, distal margin sinuous.

Phallic apparatus. Ventral lamina shorter than dorsal lamina, digitiform (dorsal view); dorsal lamina with prominent median bulge and straight distal edge (Fig. 5D); internal sclerite strong and globular; phallotremal sclerite well developed including an indistinct dorsal element (Fig. 5E) and a broad plate ending in two hooks (Fig. 5D).

\section{Distribution}

Madagascar (endemic), Rianila River basin.
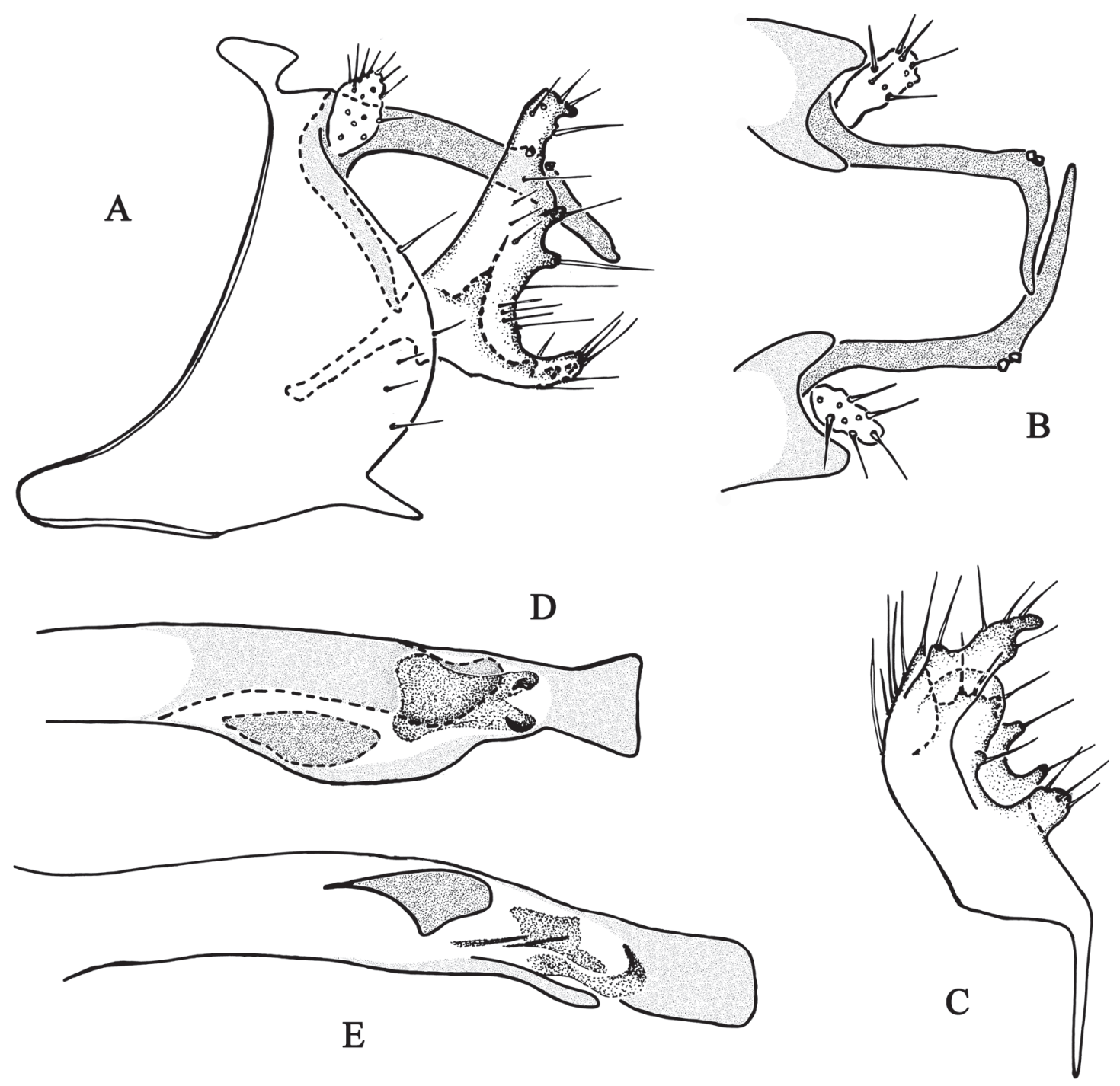

Fig. 5. Chimarra forcellinii sp. nov. A-B. Abdominal segments IX and X. A. Lateral view. B. Dorsal view. C. Inferior appendage, dorsal view. D-E. Apex of the phallic apparatus. D. Dorsal view. E. Lateral view. Scale bar $=0.5 \mathrm{~mm}$. 
Chimarra fotobohitra sp. nov.

urn:1sid:zoobank.org:act:822F3327-0079-4707-A056-9A5BD6455852

Figs 6, 17

\section{Diagnosis}

Chimarra fotobohitra sp. nov. differs from the other species of the group by the ventral branch of tergum $\mathrm{X}$, which is short and forms with the dorsal branch an angle of about $20^{\circ}$ (Fig. 6A). When it is measurable, this angle is greater than $40^{\circ}$, except in C. gattolliati sp. nov. and C. lehibemavo sp. nov.,

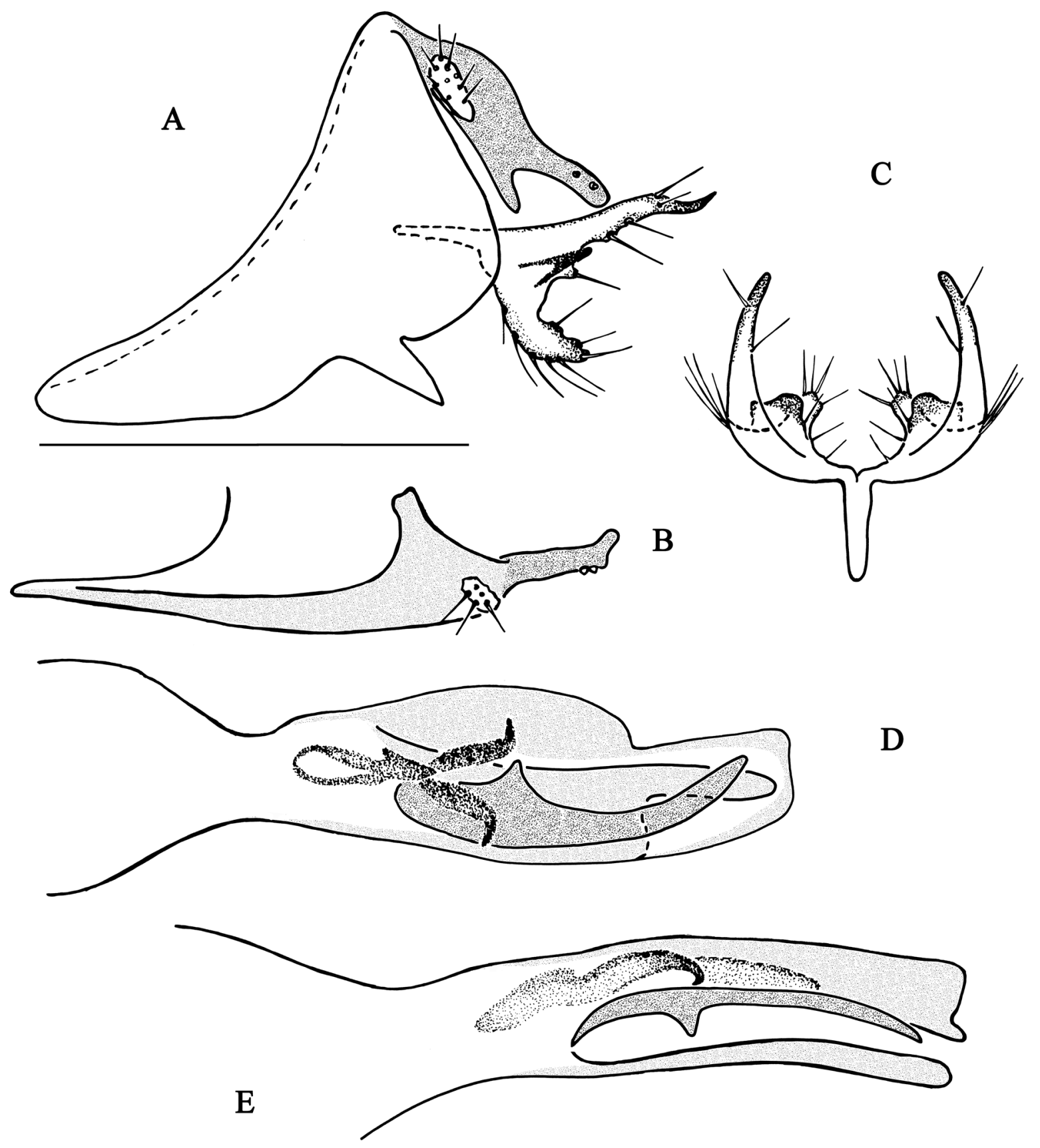

Fig. 6. Chimarra fotobohitra sp. nov. A-B. Abdominal segments IX and X. A. Lateral view. B. Dorsal view (partim). C. Inferior appendage, dorsal view. D-E. Phallic apparatus. D. Dorsal view. E. Lateral view. Scale bar $=0.5 \mathrm{~mm}$. 
where it is around $35^{\circ}$ (Fig. 7A, 2A). Another remarkable character of this species is the strong median narrowing of the dorsal lamina (Fig. 6D), also observed in C. gensonae sp. nov., but with a different shape (Fig. 8E).

\section{Etymology}

The name is that of the river where the holotype was collected.

\section{Type material}

\section{Holotype}

MADAGASCAR: $\hat{\gamma}$, wings and genitalia mounted on 4 slides, remaining parts in alcohol, Fotobohitra

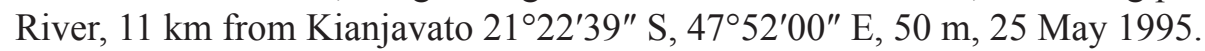

\section{Description}

Size. Forewing $5.5 \mathrm{~mm}$, hind wing $4.4 \mathrm{~mm}$.

Tergum X. When viewed laterally, lateral lobe forked after mid-length, ventral branch short, dorsal branch barely longer.

INFERIOR APPENDAGES. L-shaped, dorsal branch twice as long as ventral branch, internal lobe rounded and hump-shaped (Fig. 6C).

Phallic apparatus. Ventral lamina as long as dorsal lamina, but thinner on the lateral and dorsal views; dorsal lamina with a median narrowing (Fig. 6D); internal sclerite long, nearly as long as ventral lamina, with a little, lateral expansion; phallotremal sclerite with a basal globular part and a distal pair of hooks.

\section{Distribution}

Madagascar (endemic), Mananjary River basin.

Chimarra gattolliati sp. nov. urn:1sid:zoobank.org:act:EB25203C-33C7-4244-A74E-FBD14FB3D215

Figs 7,16

\section{Diagnosis}

Chimarra gattolliati sp. nov. is most closely related to C. jejyorum sp. nov. In both species, the lateral lobes of tergum $\mathrm{X}$ are short, the dorsal branches are small and thumb-shaped. The angle between dorsal and ventral branch is more acute in C. gattolliati sp. nov. (Fig. 7A) than in C. jejyorum sp. nov. (Fig. 9A). But this is not easy to observe, the two species are more quickly distinguished by the inferior appendages or by the phallic apparatus. In C. gattolliati sp. nov., the ventral branch of the inferior appendage is distally protruding, the dorsal branch is thin and arched (Fig. 7A); in C. jejyorum sp. nov., the ventral branch is not clearly apparent and the dorsal branch is wide and only curved towards the apex (Fig. 9A). The phallothecae of both species are split, in C. gattolliati sp. nov., this splitting occurs after mid-length (Fig. 7D), whereas, in C. jejyorum sp. nov., it occurs somewhat after the base (Fig. 9D).

\section{Etymology}

This species is dedicated to Jean-Luc Gattolliat in tribute to his work on the Malagasy may flies.

\section{Type material}

\section{Holotype}

MADAGASCAR: ${ }^{\wedge}$, mounted on 4 slides, tributary of the Manampanihy River near Fenoevo, $24^{\circ} 41^{\prime} 00^{\prime \prime}$ S, 4653'39" E, 72 m, 15 Apr. 1992, leg. J.-M. Elouard. 


\section{Paratype}

MADAGASCAR: 1 $\widehat{\text {, }}$, mounted on 4 slides, remaining parts in alcohol, Andranohela River, camp II of

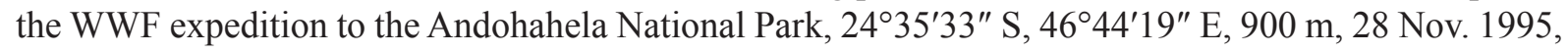
leg. J.-M. Elouard.

\section{Description}

SizE. Forewing $6.6 \mathrm{~mm}$, hind wing $5.5 \mathrm{~mm}$.

TERGUM X. Lateral lobe with wide basal part, short ventral branch and barely longer dorsal branch; when viewed dorsally, dorsal branch angled with, towards the apex, a small protuberance bearing the sensillae.

INFERIOR APPENDAGES. L-shaped (lateral view); ventral branch distally protruding; dorsal branch thin and regularly arched.
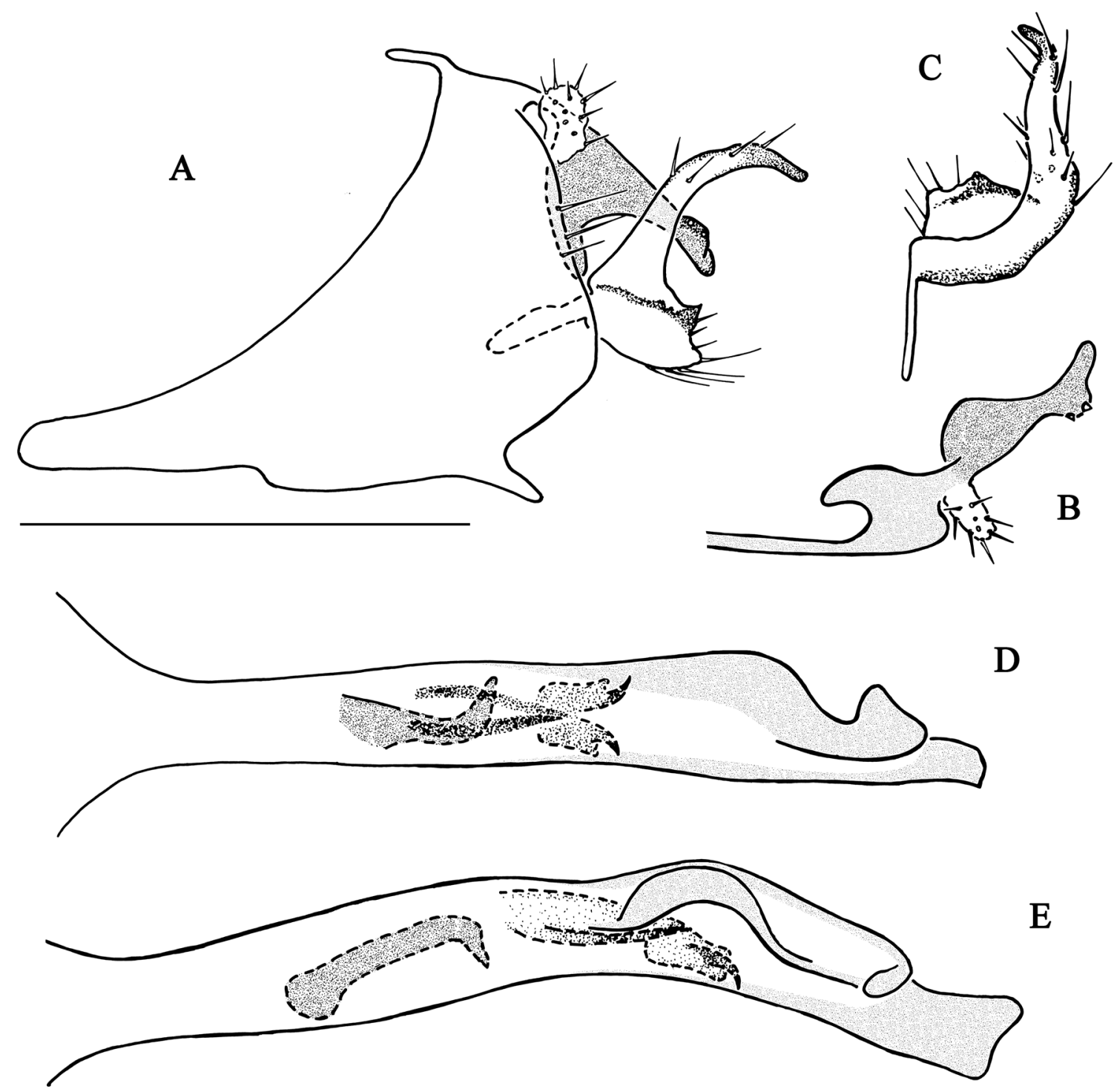

Fig. 7. Chimarra gattolliati sp. nov. A-B. Abdominal segments IX and X. A. Lateral view. B. Dorsal view (partim). C. Inferior appendage, dorsal view. D-E. Phallic apparatus. D. Dorsal view. E. Lateral view. Scale bar $=0.5 \mathrm{~mm}$. 
Phallic apPaRatus. Phallotheca split after mid-length; ventral lamina longer than dorsal lamina, dorsal lamina with a lateral fold (Fig. 7E) and an apical curvature (Fig. 7D); phallotremal sclerite with basal part flanked by two indistinct small needles and extended by a pair of hooks; internal sclerite long and stout, with apical curvature, slightly shorter than phallotremal sclerite.

\section{Distribution}

Madagascar (endemic), Andohahela National Park and surrounding areas.

Chimarra gensonae sp. nov. urn:Isid:zoobank.org:act:D0D40DA2-B53D-4699-812D-A4BA6B5C80EF

Figs 8,18

\section{Diagnosis}

Chimarra gensonae sp. nov. is closely related to C. tamara sp. nov. When viewed laterally, their tergum $\mathrm{X}$ are very similar, characterized by a thick and short dorsal branch and a thin ventral branch (Figs $8 \mathrm{~A}$, 14A). The two species differ by the phallotheca, short and stout in C. gensonae sp. nov. (Fig. 8D-E), long and slim in C. tamara sp. nov. (Fig. 14D-E).

\section{Etymology}

It is a pleasure to dedicate this species to my colleague Gwenaelle Genson in recognition of her efforts for the barcoding of caddisflies.

\section{Type material}

\section{Holotype}

MADAGASCAR: ${ }^{\lambda}$, mounted on 2 slides, remaining parts in alcohol, Tamara River, $4 \mathrm{~km}$ from

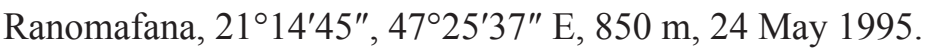

\section{Paratypes}

MADAGASCAR: $3 \hat{\partial} \hat{\sigma}^{\lambda}$, same data as holotype, in alcohol; $1 \hat{\partial}$, Ambatoharanana River near Ranomafana, $21^{\circ} 15^{\prime} 15^{\prime \prime} \mathrm{S}, 47^{\circ} 27^{\prime} 34^{\prime \prime} \mathrm{E}, 850$ m, 23 May 1995.

\section{Other specimens}

MADAGASCAR: 1 , mounted on 3 slides, remaining parts in alcohol, Ranomafana National Park,

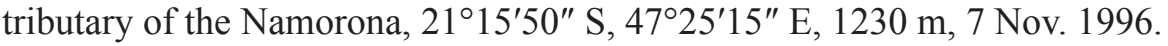

\section{Description}

SizE. Forewing $7.6 \mathrm{~mm}$, hind wing $6.0 \mathrm{~mm}$.

Tergum X. Dorsal branch wide and short, thumb-shaped when viewed laterally, toward the apex a small protuberance with two sensillae; ventral branch thin as long as dorsal branch; dorsal and ventral branches forming an angle of $65^{\circ}$.

INFERIOR APPENDAGES. Roughly triangular, anterior margin almost twice as long as ventral margin; dorsal part curved distad, inner lobe long, thin, slightly protruding.

Phallic APparatus. Short compared to other species of the group. Phallotheca split nearly from the base; ventral lamina as long as dorsal lamina, thinner and digitiform; when viewed dorsally, dorsal lamina with a lateral fold and a sudden narrowing after mid-length (Fig. 8D); internal sclerite short, stout, 
bullet-shaped (Fig. 8E); phallotremal sclerite including an ovoid basal part, a thin spine and a pair of hooks.

\section{Distribution}

Madagascar (endemic), Ranomafana National Park and surroundings areas.

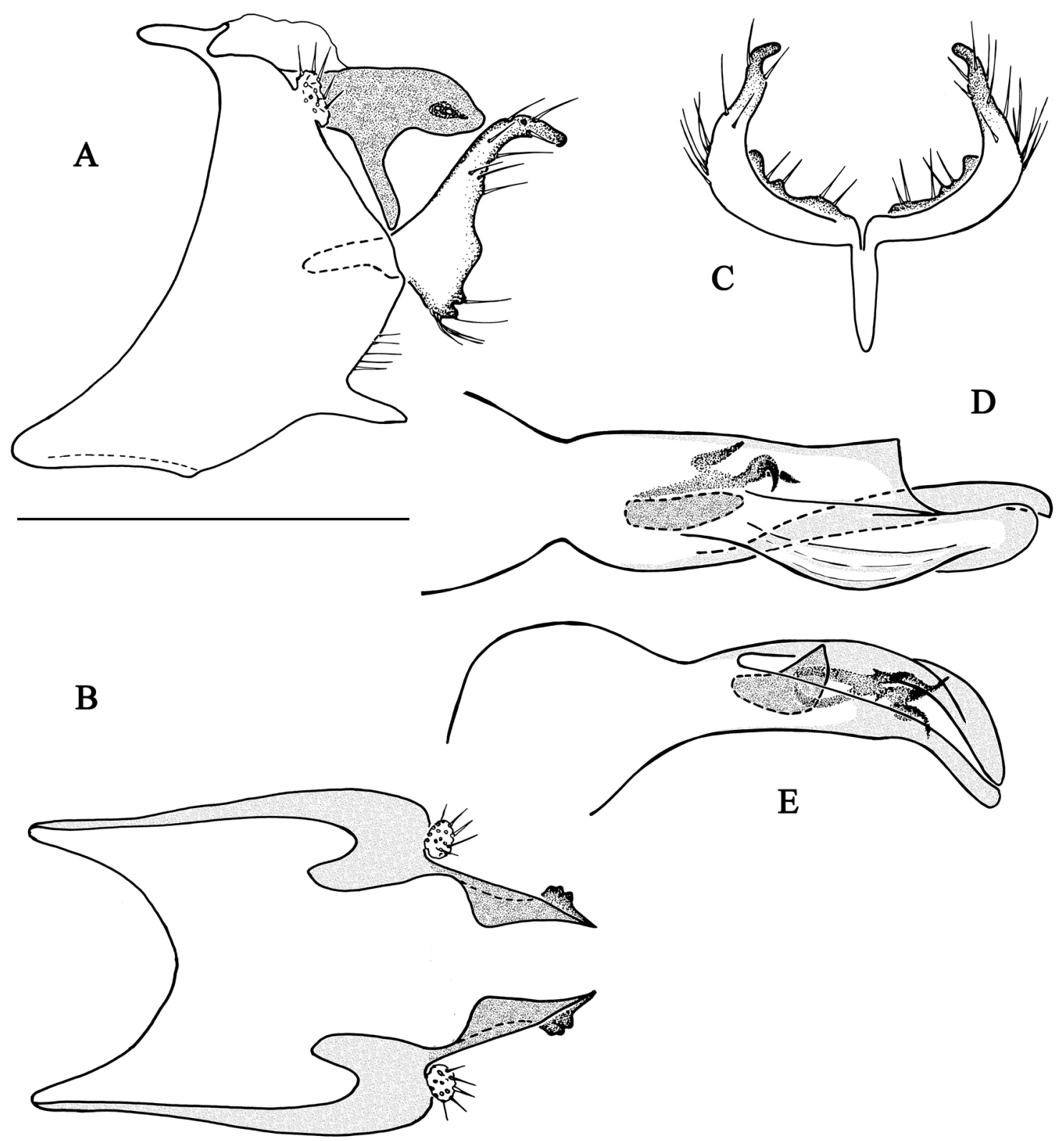

Fig. 8. Chimarra gensonae sp. nov. A-B. Abdominal segments IX and X. A. Lateral view. B. Dorsal view. C. Inferior appendages, dorsal view. D-E. Phallic apparatus. D. Dorsal view. E. Lateral view. Scale bar $=0.5 \mathrm{~mm}$. 


\section{Chimarra jejyorum sp. nov. urn:1sid:zoobank.org:act:714C3E34-8FCB-451E-8A19-10F61A1DF016} Figs 1, 9, 18

\section{Diagnosis}

Chimarra jejyorum sp. nov. is closely related to C. gattolliati sp. nov. The two species can be distinguished by the shape of the inferior appendages, as discussed in the diagnosis of $C$. gattolliati sp. nov. or, due to the size of the phallic apparatus, by the phallotheca, split shortly after the base in C. jejyorum sp. nov. (Fig. 9D), after mid-length in C. gattolliati sp. nov. (Fig. 7D).

\section{Etymology}

From the Malagasy 'jejy' (a traditional musical instrument). It is a reference to the name of the Mountain Marojejy, in translation: where there are many guitars.

\section{Type material}

\section{Holotype}

MADAGASCAR: $\widehat{\partial}$, mounted on 3 slides, remaining parts in alcohol, camp II of the WWF expedition to the Marojejy National Park, $14^{\circ} 26^{\prime} 10^{\prime \prime}$ S, 4945'37" E, 750 m, 14 Oct. 1996, leg. D. Randriamasimanana and J. Legrand.

\section{Paratypes}

MADAGASCAR: $7 \hat{\partial} \hat{\partial}$, in alcohol, same data as holotpye; $1 \hat{\partial}$, camp I of the WWF expedition to the Marojejy National Park, $14^{\circ} 26^{\prime} 02^{\prime \prime}$ S, 4946'20" E, 450 m, 13 Oct. 1996, leg. D. Randriamasimanana and J. Legrand.

\section{Other specimens}

MADAGASCAR: $1 \hat{\sigma}$, mounted on 2 slides, remaining parts in alcohol, Andranomifitatra River, camp III of the WWF expedition to the Marojejy National Park, 14²6'02" S, 49 $44^{\prime} 05^{\prime \prime}$ E, 1225 m, 25 Oct. 1996, leg. D. Randriamasimanana and J. Legrand.

\section{Description}

Size. Forewing $7.3 \mathrm{~mm}$, hind wing $5.8 \mathrm{~mm}$.

TERgum X. Ventral branch of lateral lobe short, dorsal branch thumb-shaped, slightly curved ventrad (lateral view), apex contorted with two sensillae (Fig. 9B).

INFERIOR APPENDAGES. Ventral branch reduced, dorsal apex with small denticles.

Phallic APPARATus. Phallotheca split according to a sagittal plane, right lamina large with a big dorsolateral bump, left lamina nearly as long but thinner (dorsal view); internal sclerite sickle-shaped (lateral view); phallotremal sclerite present, sclerotized but indistinctly shaped.

\section{Distribution}

Madagascar (endemic), Marojejy National Park. 

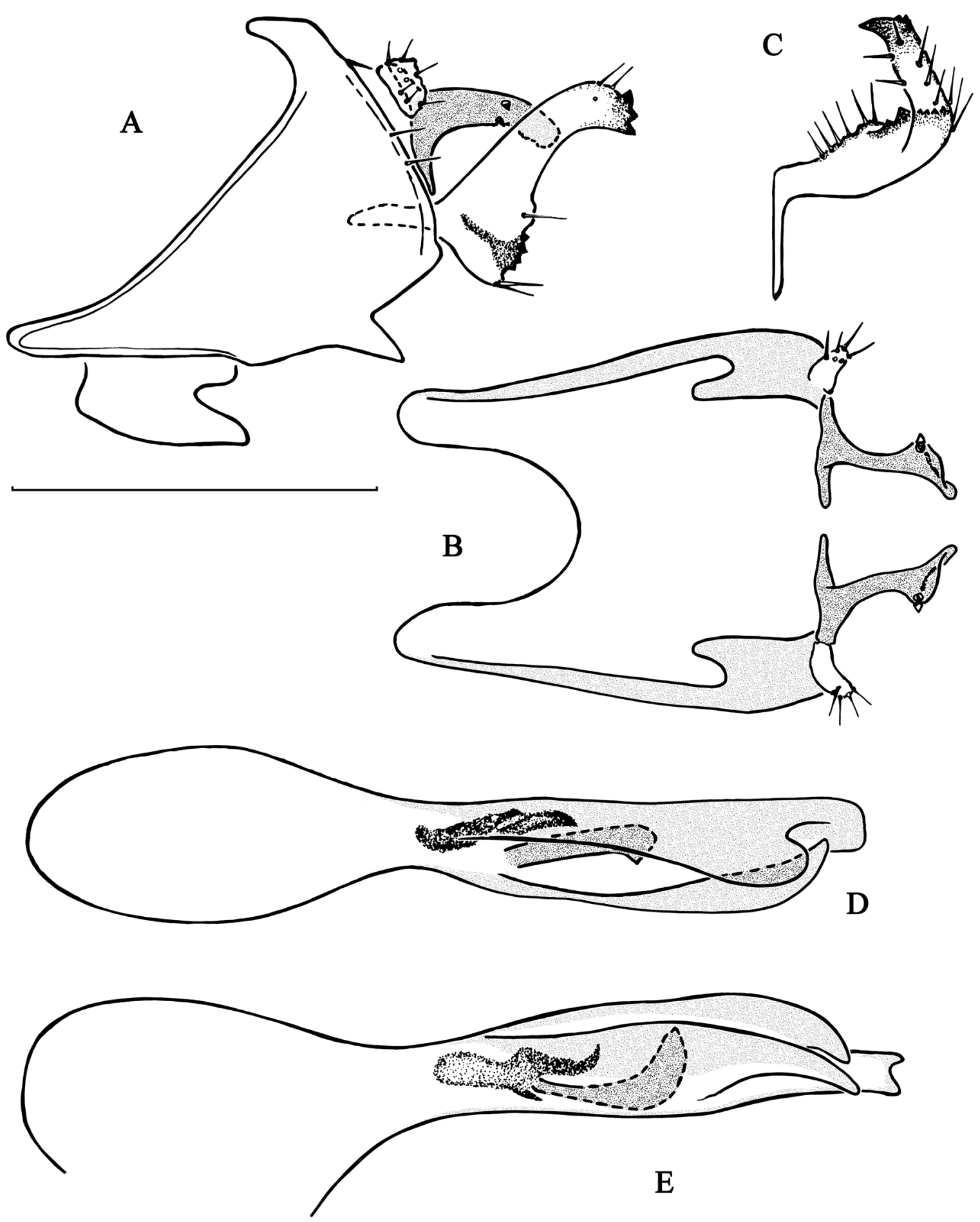

Fig. 9. Chimarra jejyorum sp. nov. A-B. Abdominal segments IX and X. A. Lateral view with ventral margin of sternite VIII. B. Dorsal view. C. Inferior appendage, dorsal view. D-E. Phallic apparatus. D. Dorsal view. E. Lateral view. Scale bar $=0.5 \mathrm{~mm}$. 
Chimarra hamatra sp. nov.

urn:lsid:zoobank.org:act:EA3CF81A-84AF-4AF0-8997-F48E8E00ADB4

Figs 10,17

\section{Diagnosis}

The closest species to $C$. hamatra sp. nov. is $C$. makiorum sp. nov. The tergum $\mathrm{X}$ of these two species are relatively small (as in $C$. jejyorum sp. nov. and in $C$. gattolliati sp. nov.) but, their inferior appendages are roughly rectangular and not triangular or L-shaped as in all the other species of the group. Moreover,

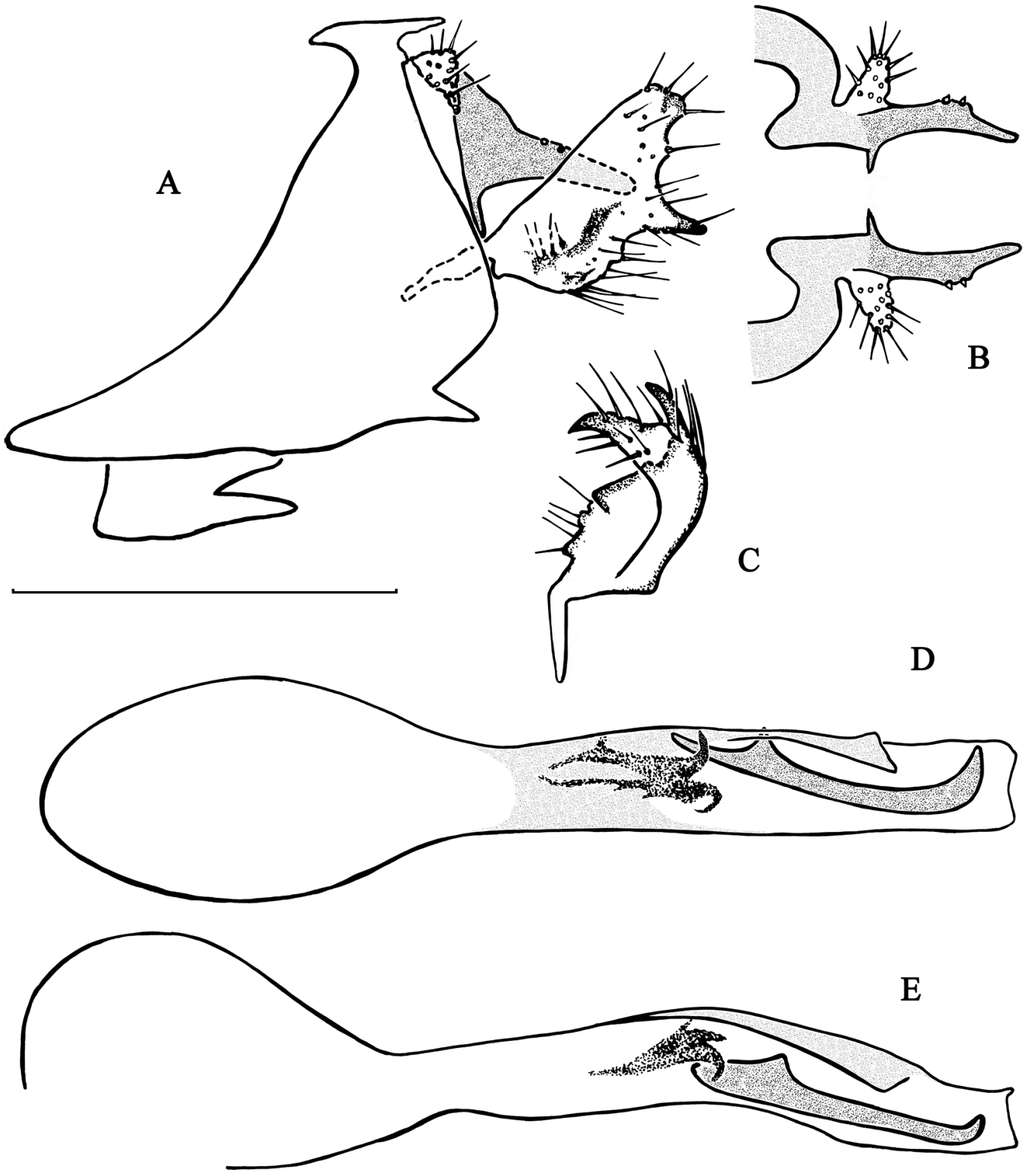

Fig. 10. Chimarra hamatra sp. nov. A-B. Abdominal segments IX and X. A. Lateral view with ventral margin of sternite VIII. B. Dorsal view. C. Inferior appendage, dorsal view. D-E. Phallic apparatus. D. Dorsal view. E. Lateral view. Scale bar $=0.5 \mathrm{~mm}$. 
these appendages have a distinct and heavily sclerotized supplementary branch on the distal edge. This branch is inserted at mid-height in C. hamatra sp. nov. (Fig. 10A), whereas almost apically in C. makiorum sp. nov. (Fig. 11A).

\section{Etymology}

The name is a Malagasy adjective that means 'uncommon'.

\section{Type material}

\section{Holotype}

MADAGASCAR: $\widehat{ }$, mounted on three slides, tributary of the Sahatandra River, near Moramanga, $18^{\circ} 56^{\prime} 27^{\prime \prime}$ S, 48 29'12" E, 800 m, 28 Apr. 1998, leg. J.-M. Elouard.

\section{Description}

SIzE. Forewing $7.1 \mathrm{~mm}$, hind wing $5.6 \mathrm{~mm}$.

Tergum X. Lateral lobe reduced; dorsal branch straight (lateral view), relatively short with, at midlength, a small lateral bump bearing two sensillae; ventral branch short and thin.

INFERIOR APPENDAGES. Wide, roughly rectangular in lateral view; ventral branch weakly developed; median branch protruding, inserted on distal edge (lateral view), making the apex claw-shaped on dorsal view (Fig. 10C).

Phallic APparatus. Long, distal half of the phallotheca poorly sclerotized with the exception of a strip terminated by a triangular tip; internal sclerite long, with a basal triangular extension and curved apex; phallotremal sclerite relatively small, ending in a pair of hooks.

\section{Distribution}

Madagascar (Moramanga area).

$$
\begin{aligned}
& \text { Chimarra makiorum sp. nov. } \\
& \text { urn:Isid:zoobank.org:act:0874DFCB-4167-488F-8CD8-8F668E4EAE0F }
\end{aligned}
$$
Figs 11,18

\section{Diagnosis}

Chimarra makiorum sp. nov. differs from C. hamatra sp. nov. by the apical insertion of the median branch of the inferior appendage (at mid-height in C. makiorum sp. nov.).

\section{Etymology}

The name is designed from that of the river where the type was collected (Rivière des makis). It is used according to the Latin rules.

\section{Type material}

\section{Holotype}

MADAGASCAR: 0 , mounted on 3 slides, Montagne d'Ambre, camp I of the WWF expedition to the Park, Makis River, $12^{\circ} 31^{\prime} 40^{\prime \prime}$ S, 49¹0'09" E, 1075 m, 31 Mar. 1995, leg. J.-M. Elouard.

\section{Paratypes}

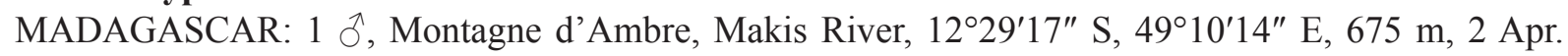

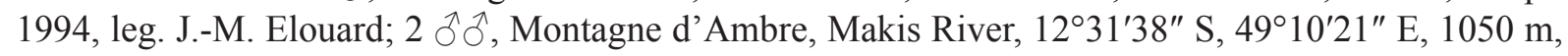
leg. J.-M. Elouard. 


\section{Description}

Size. Forewing $7.0 \mathrm{~mm}$, hind wing $5.5 \mathrm{~mm}$.

Tergum X. Lateral lobe with reduced ventral branch and short dorsal branch; dorsal branch straight (lateral and dorsal view), with a lateral bump bearing two sensillae.

INFERIOR APPENDAGES. Wide, roughly rectangular in lateral view; ventral branch weakly developed; median branch protruding, inserted near the apex of distal edge (lateral view), making the apex clawshaped on dorsal view (Fig. 11C).

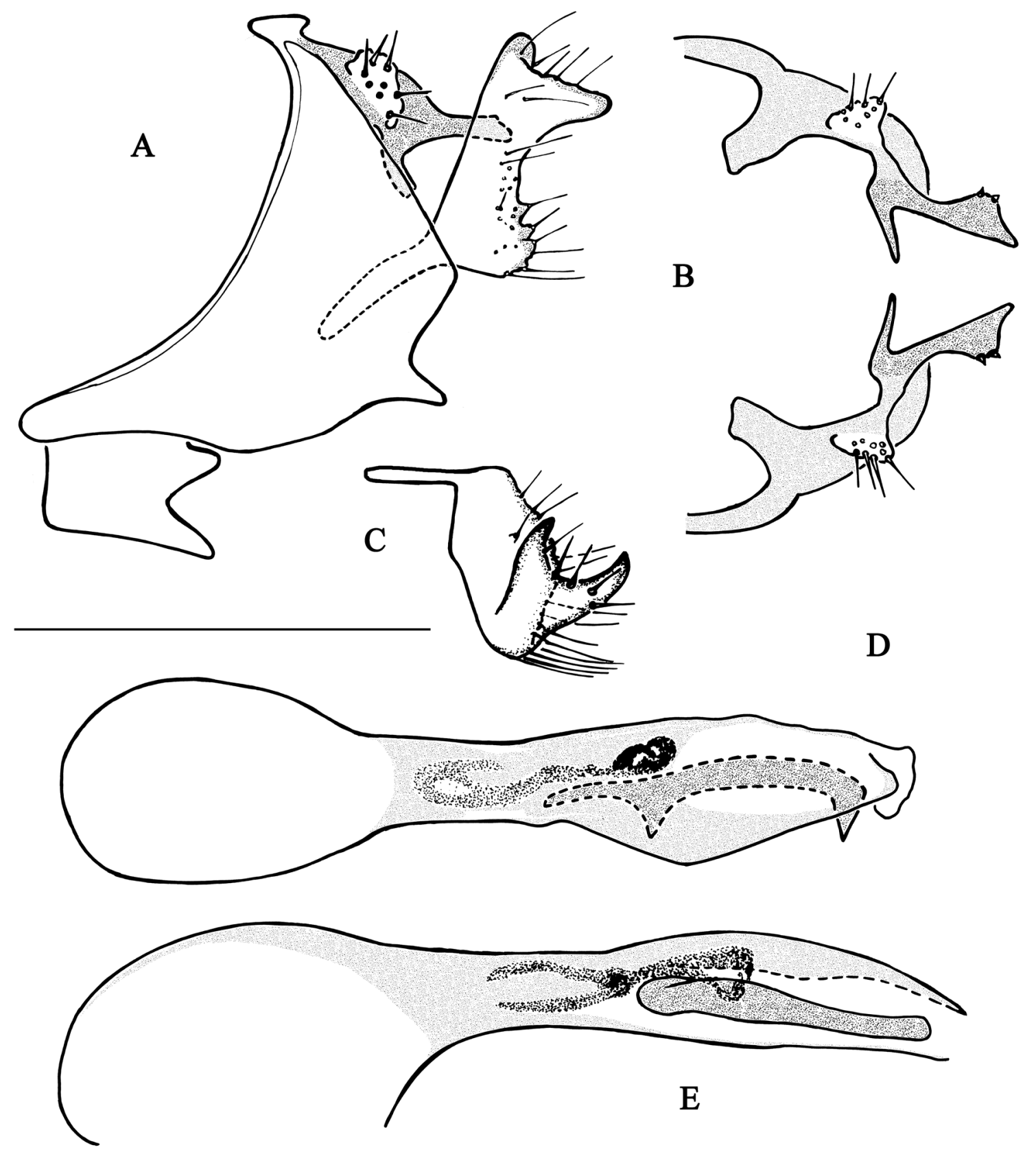

Fig. 11. Chimarra makiorum sp. nov. A-B. Abdominal segments IX and X. A. Lateral view with ventral margin of sternite VIII. B. Dorsal view (partim). C. Inferior appendage, dorsal view. D-E. Phallic apparatus. D. Dorsal view. E. Lateral view. Scale bar $=0.5 \mathrm{~mm}$. 
Phallic ApPARatus. Long, distal half of the phallotheca poorly sclerotized with the exception of the dorsal part, whose left edge is laterally extended; internal sclerite long, with a basal triangular extension and curved apex; phallotremal sclerite relatively long (as long as half of the phallotheca).

\section{Distribution}

Madagascar (endemic), Montagne d'Ambre.

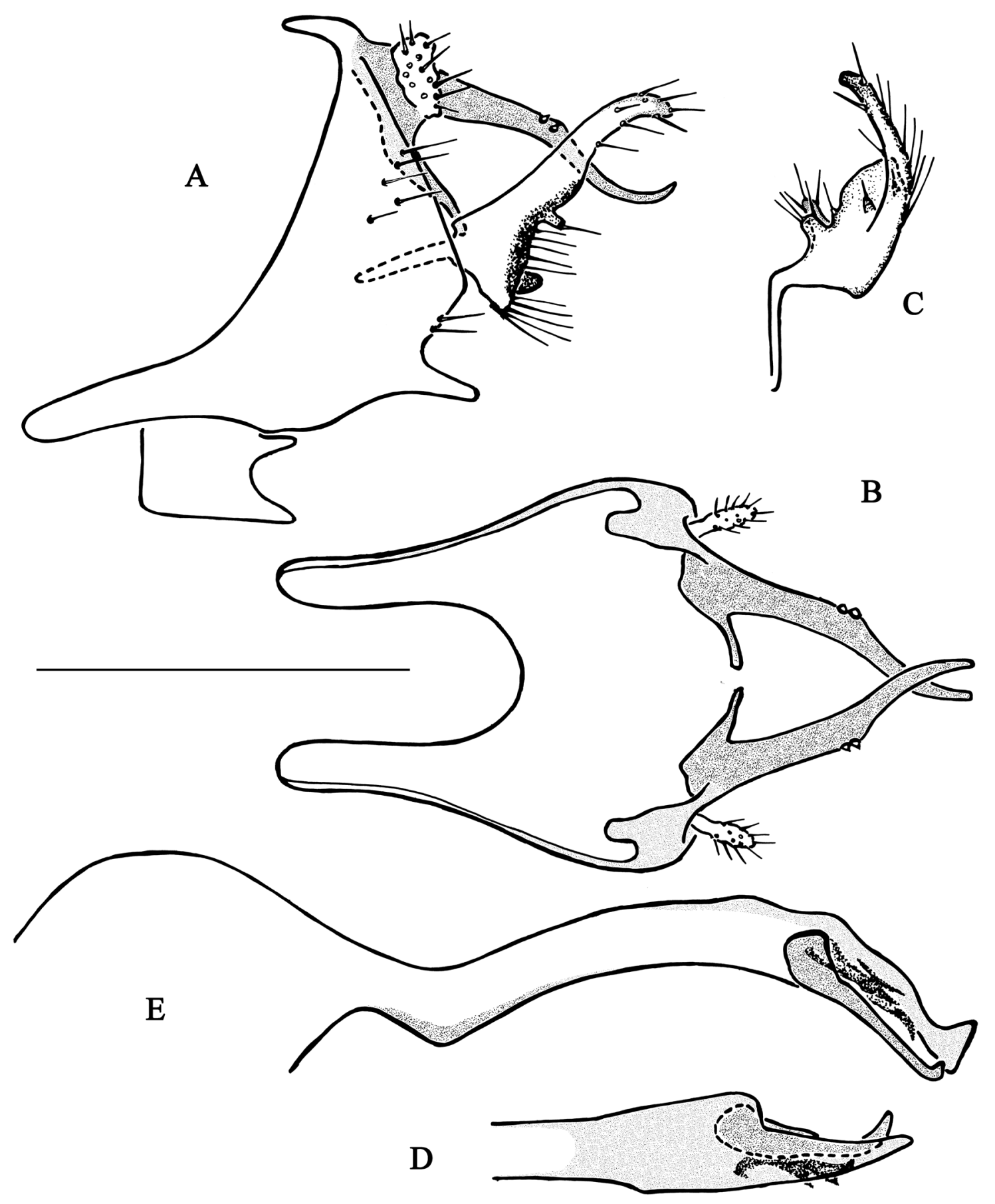

Fig. 12. Chimarra moramanga sp. nov. A-B. Abdominal segments IX and X. A. Lateral view. B. Dorsal view. C. Inferior appendage, dorsal view. D-E. Phallic apparatus. D. Apex, dorsal view. E. Lateral view. Scale bar $=0.5 \mathrm{~mm}$. 


\section{Chimarra moramanga sp. nov. urn:Isid:zoobank.org:act:D6E697EE-4F4D-42EA-A250-0F513A73CB18}

Figs 12,17

\section{Diagnosis}

Chimarra moramanga sp. nov. differs from the other species of the lehibemavo group by the strongly bent base of the tubular part of the phallic apparatus (Fig. 12D).

\section{Etymology}

The name is that of the nearest city to the type locality.

\section{Type material}

\section{Holotype}

MADAGASCAR: $\widehat{\gamma}$, mounted on three slides, tributary of the Sahatandra River, near Moramanga, $18^{\circ} 56^{\prime} 27^{\prime \prime}$ S, 48²9'12" E, 800 m, 28 Apr. 1998, leg. J.-M. Elouard.

\section{Description}

Size. Forewing $6.4 \mathrm{~mm}$, hind wing $5.0 \mathrm{~mm}$.

TERgum X. Dorsal branch of the lateral lobe long (twice as long as the ventral branch), basal part straight, proximal part gently curved dorsad (lateral view), a small bump with two sensillae just before the curvature.

INFERIOR APPENDAGE. Triangular with long anterior margin and short ventral margin, dorsal apex slightly curved distad, inner lobe large and rounded (dorsal view).

Phallic apparatus. Phallotheca strongly angled at base, then gently bent ventrad, distal part (one third of the length) poorly sclerotized with the exception of a dorsal strip with triangular apex (lateral view, Fig. 12D); internal sclerite as long as the modified distal part of the phallotheca, with enlarged base and curved apex; phallotremal sclerite shorter than the internal sclerite.

\section{Distribution}

Madagascar (endemic), Moramanga area.

Chimarra saha sp. nov. urn:1sid:zoobank.org:act:8CED47DC-B04D-4163-9759-F1AE96D400B1

Figs 13,17

\section{Diagnosis}

By most of its characters, $C$. saha sp. nov. is closely related to C. moramanga sp. nov. The remarkable structure of the phallic apparatus of this latter prevents any confusion between the two species. Moreover, C. saha sp. nov. is characterized by the laterally deflected dorsal lamina of the phallotheca. This deflection makes the distal part of the apparatus wider than the median part (dorsal view).

\section{Etymology}

From the Malagasy 'saha' (= valley), referring to the name of the type-river, used as a noun in apposition. 


\section{Type material}

\section{Holotype}

MADAGASCAR: $\sigma^{\lambda}$, mounted on 2 slides, remaining parts in alcohol, Sahanivoraky River, $22^{\circ} 13^{\prime} 33^{\prime \prime} \mathrm{S}$, 4700'41" E, 810 m, 19 Nov. 1993.

\section{Description}

Size. Forewing $7.5 \mathrm{~mm}$, hind wing $5.9 \mathrm{~mm}$.

TERGUM X. Dorsal branch of the lateral lobe long (twice as long as the ventral branch), bent ventrad at mid-length with a dorsad curved apex (lateral view).

INFERIOR APPENDAGE. Triangular with long anterior margin, short ventral margin and a small triangular point on distal edge, dorsal apex slightly curved distad, inner lobe large and rounded (dorsal view).
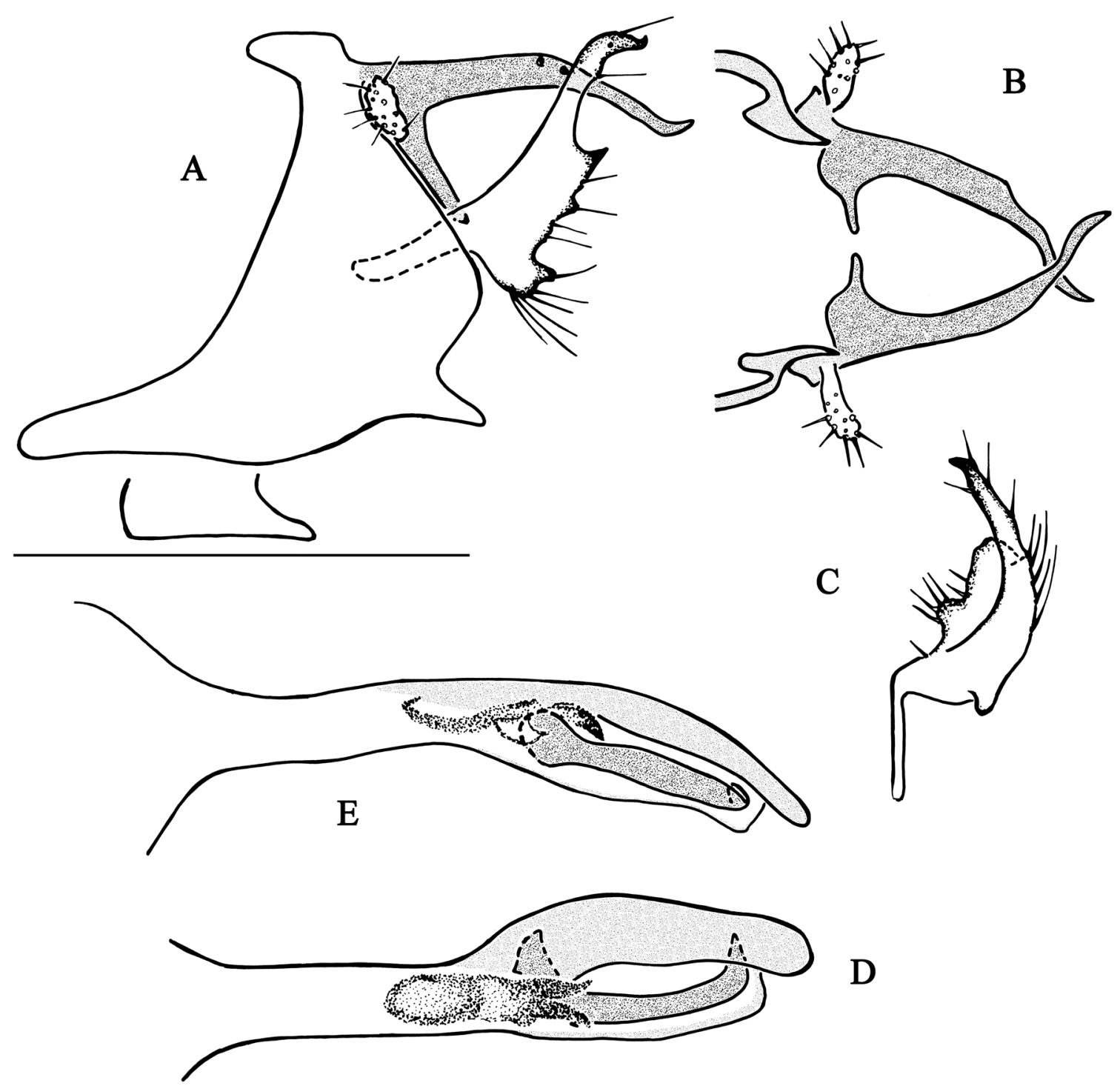

Fig. 13. Chimarra saha sp. nov. A-B. Abdominal segments IX and X. A. Lateral view with ventral margin of sternite VIII. B. Dorsal view (partim). C. Inferior appendage, dorsal view. D-E. Phallic apparatus. D. Dorsal view. E. Lateral view. Scale bar $=0.5 \mathrm{~mm}$. 
Phallic APparatus. Phallotheca split at mid-length; dorsal lamina wide, digitiform and laterally deflected; ventral lamina shorter and less sclerotized than dorsal lamina; internal sclerite long; phallotremal sclerite short, with stout pair of hooks.

\section{Distribution}

Madagascar (endemic), Andringitra National Park.

Chimarra tamara sp. nov. urn:1sid:zoobank.org:act:3C9A5123-F396-4540-8276-6FB2E892DE62

Figs 14, 16

\section{Diagnosis}

Chimarra tamara sp. nov. differs from $C$. gensonae sp. nov. by the long and slim tubular part of the phallic apparatus.

\section{Etymology}

The name is that of the Tamara River, one of those where the species was collected.

\section{Type material}

\section{Holotype}

MADAGASCAR: ${ }^{\lambda}$, genitalia on 2 slides, remaining parts in alcohol, tributary of the Sahavatoy River, Camp III of the WWF expedition to the Andringitra National Park, $22^{\circ} 12^{\prime} 50^{\prime \prime} \mathrm{S}, 46^{\circ} 58^{\prime} 30^{\prime \prime} \mathrm{E}, 1210 \mathrm{~m}$, 22 Nov. 1993.

\section{Paratypes}

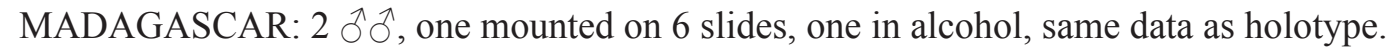

\section{Other specimens}

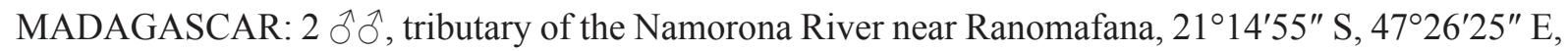

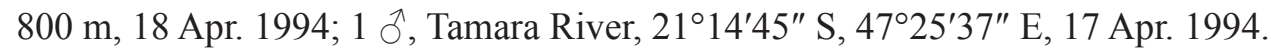

\section{Description}

SIzE. Forewing $7.3 \mathrm{~mm}$, hind wing $5.9 \mathrm{~mm}$.

TERGUM X. Ventral branch of lateral lobe small, dorsal branch in direct continuity from the base; when viewed dorsally, apex slightly enlarged, bearing a small protuberance with two sensillae.

INFERIOR APPENDAGE. Dorsal apex curved distad and protruding ventral part (lateral view), inner lobe long forming a serrated big bump on the dorsal view (Fig. 14C).

Phallic apPaRatus. Phallotheca slim and long, split after mid-length; ventral lamina twisted with acute apex, slightly longer than dorsal lamina; phallotremal and internal sclerites relatively small; internal sclerite slightly longer than phallotremal sclerite, apex curved.

\section{Distribution}

Madagascar (endemic), Andringitra and Namorona National Park. 


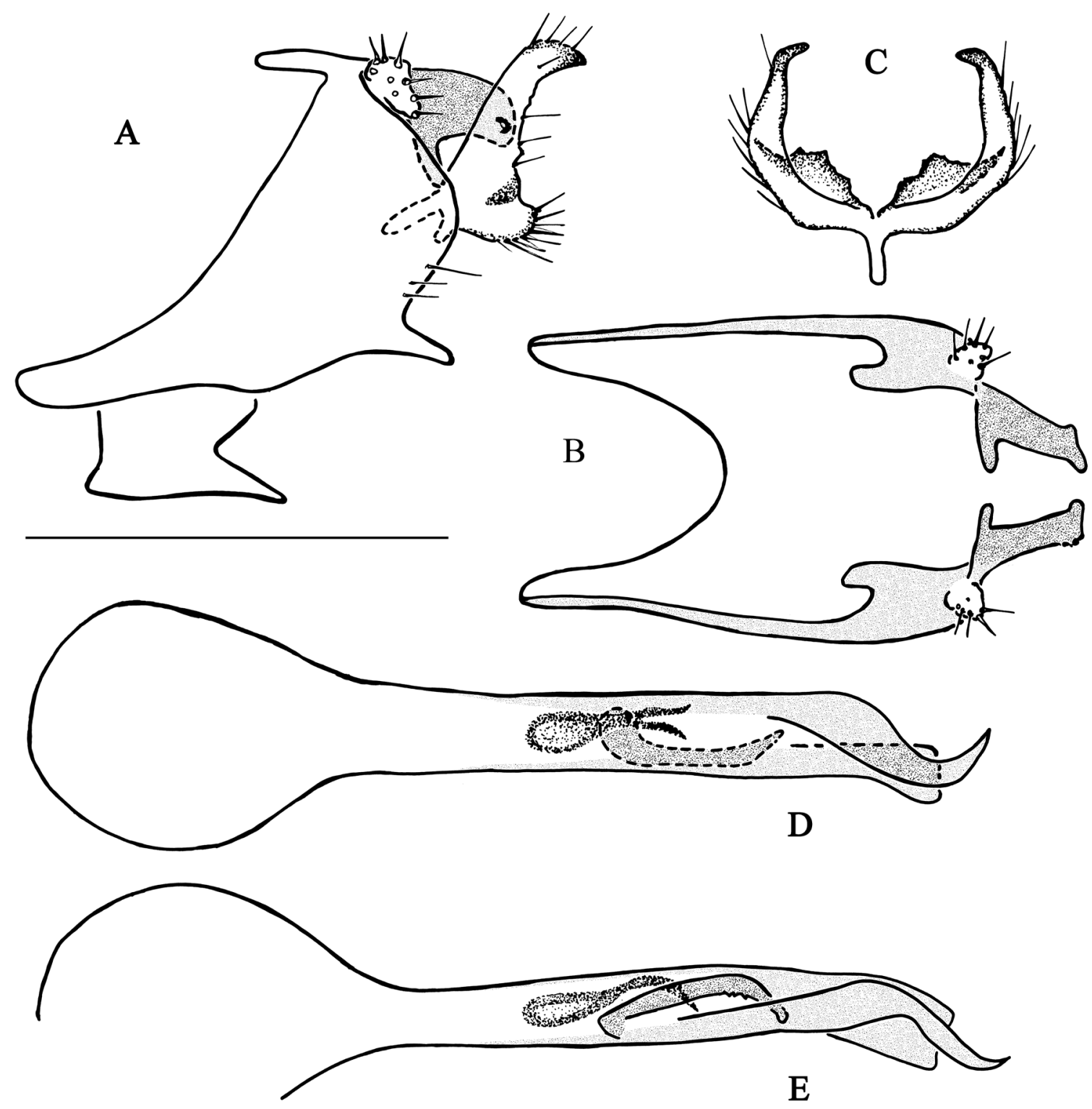

Fig. 14. Chimarra tamara sp. nov. A-B. Abdominal segments IX and X. A. Lateral view with ventral margin of sternite VIII. B. Dorsal view. C. Inferior appendage, dorsal view. D-E. Phallic apparatus. D. Dorsal view. E. Lateral view. Scale bar $=0.5 \mathrm{~mm}$.

\section{Geographic Data}

Geographic and ecological information on the lehibemavo group are summarized on figures 15 to 18 . With one exception discussed thereafter ( $C$. fenoevo sp. nov.), the species live in small streams of the oriental rainforests, where they have narrow latitudinal distributions. From the north to the south of the Island, appears a sequence of species or small groups of species:

- Amber Mountain, C. makiorum sp. nov.

- Marojejy, C. cebegepi sp. nov., C. jejyorum sp. nov., C. lehibemavo sp. nov.

- Moramanga area, C. hamatra sp. nov., C. moramanga sp. nov., C. forcellinii sp. nov.

- Ranomafana, C. gensonae sp. nov., C. tamara sp. nov.

- Andringitra, C. saha sp. nov., C. tamara sp. nov.

- Andohahela, C. gattolliati sp. nov. 

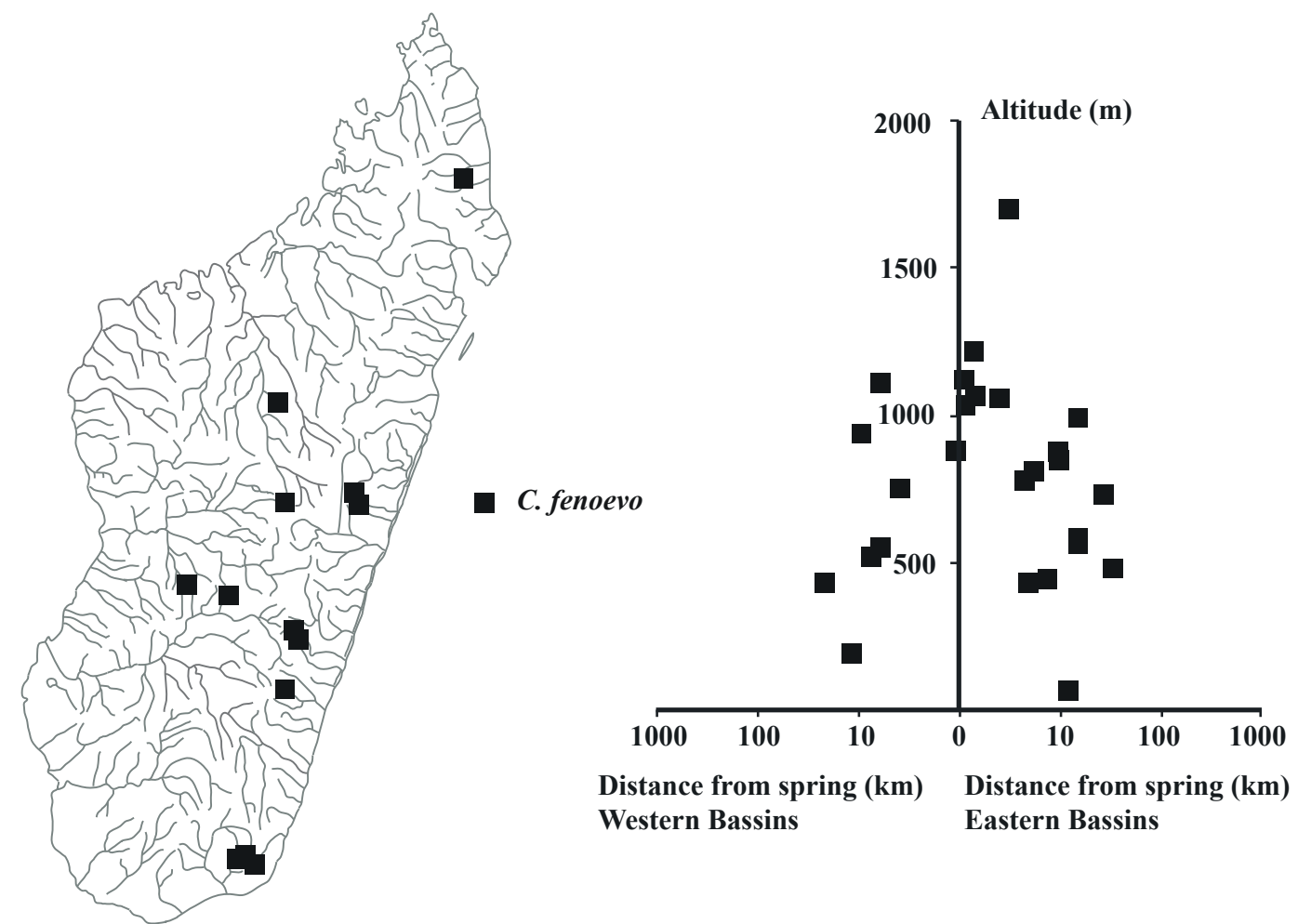

Fig. 15. Chimarra fenoevo sp. nov., schematic distribution map and ecological profile of the capture sites in Madagascar.

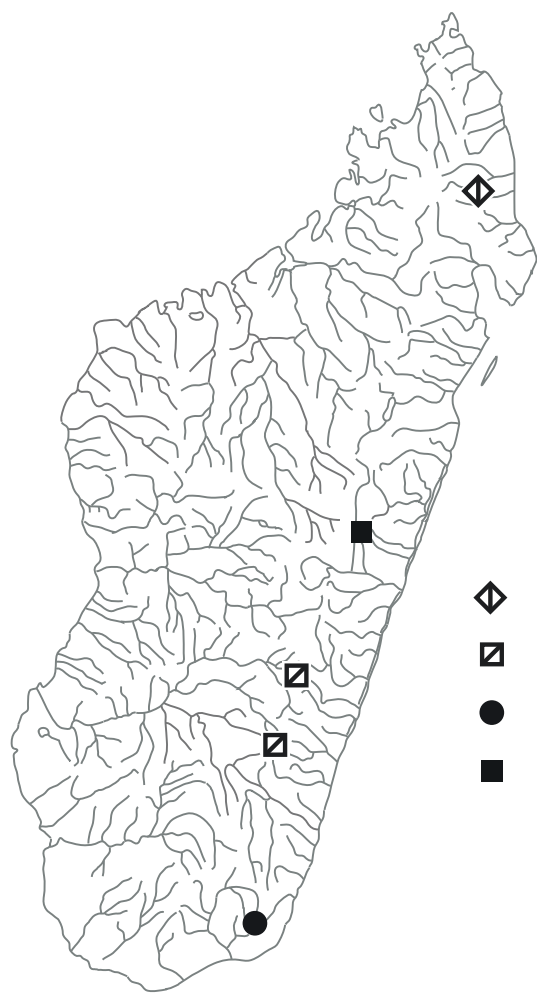

\section{C. lehibemavo}

C. tamara

C. gattolliati

C. forcellinii

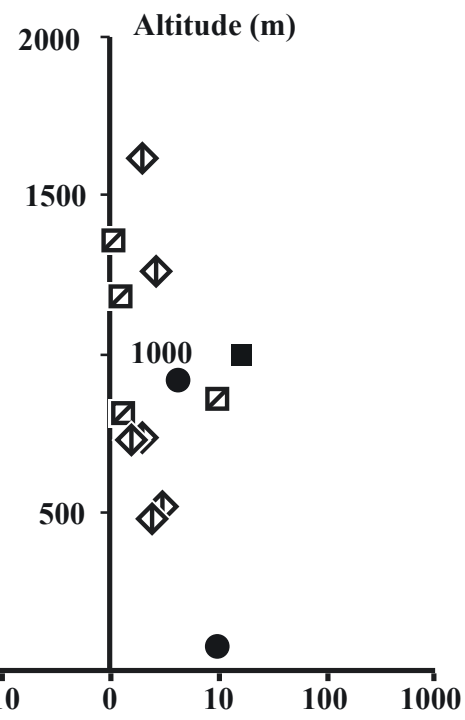

Distance from spring $(\mathbf{k m}) \quad$ Distance from spring $(\mathbf{k m})$ Western Bassins

Eastern Bassins

Fig. 16. Chimarra lehibemavo sp. nov., Chimarra tamara sp. nov., Chimarra gattolliati sp. nov. and Chimarra forcellinii sp. nov., schematic distribution map and ecological profile of the capture sites in Madagascar. 


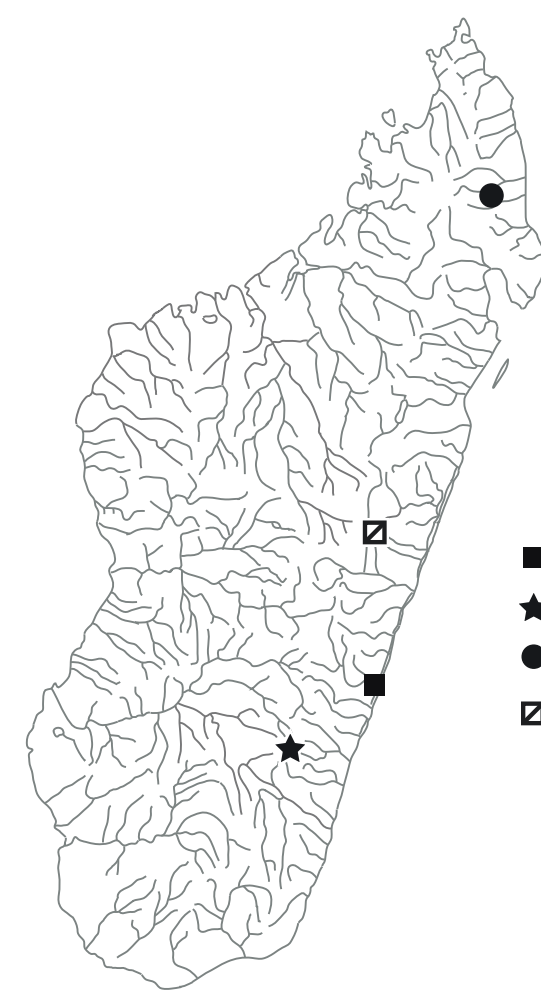

C. fotobohitra

C. saha

C. cebegepi

\C. moramanga

C. hamatra

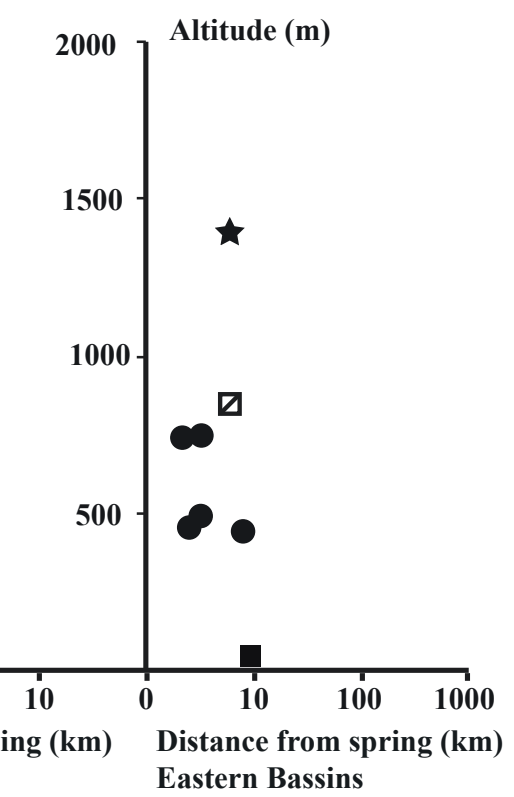

Fig. 17. Chimarra fotobohitra sp. nov., Chimarra saha sp. nov., Chimarra hamatra sp. nov., Chimarra moramanga sp. nov. and Chimarra cebegepi sp. nov., schematic distribution map and ecological profile of the capture sites in Madagascar.
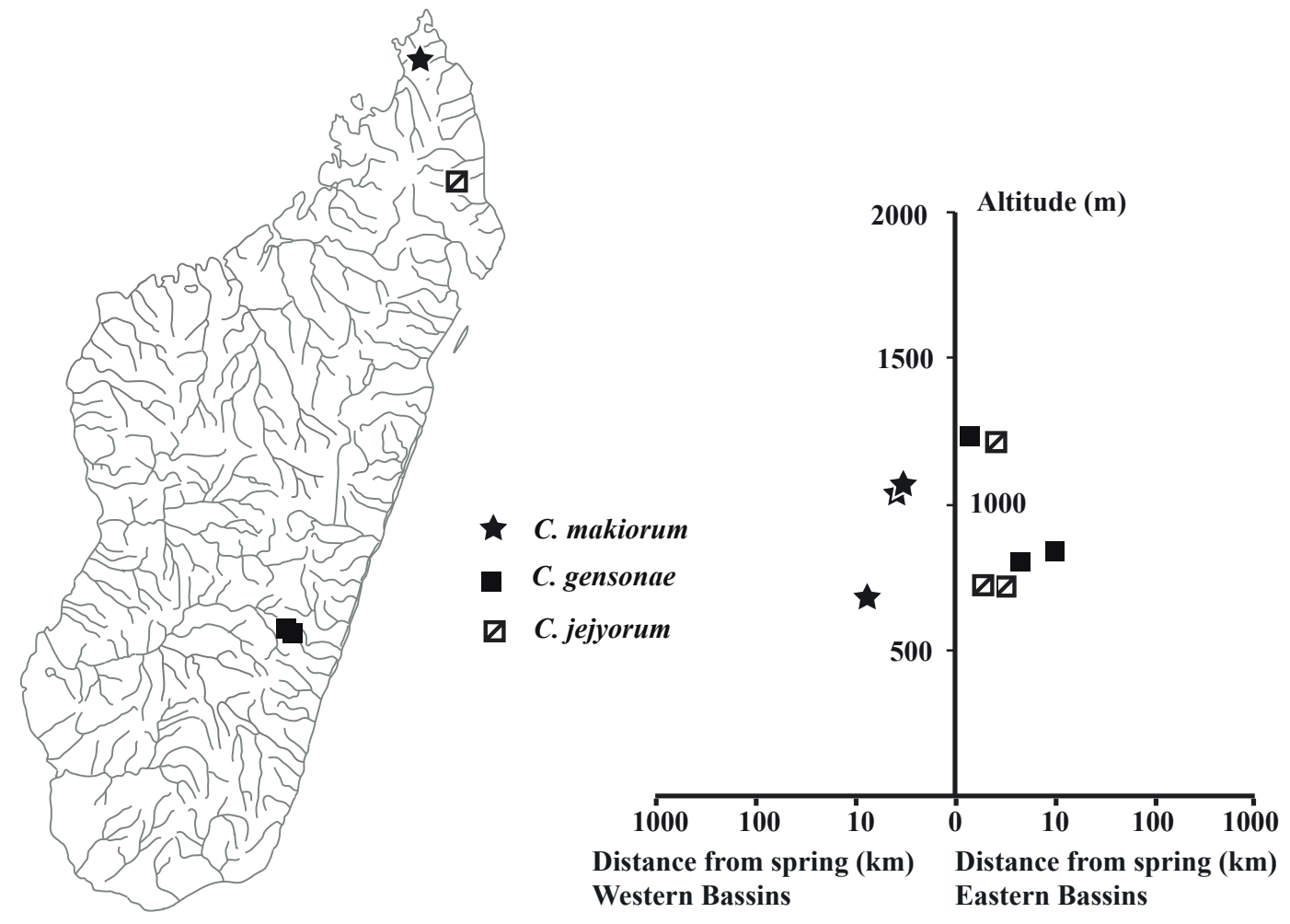

Fig. 18. Chimarra makiorum sp. nov., Chimarra gensonae sp. nov. and Chimarra jejyorum sp. nov., schematic distribution map and ecological profile of the capture sites in Madagascar. 
Such an eco-geographic pattern was already observed, described and discussed for the Rossinae and for the Philopotaminae (Gibon \& Elouard 1996; Gibon 2013, 2014). Compared to the genera Rossodes Oezdikmen \& Darilmaz, 2008, Wormaldia McLachlan, 1865 and Ranarijaodes Gibon, 2014, the lehibemavo group offers a less extreme situation. One species, C. tamara sp. nov., was captured in two adjacent areas (Andringitra and Ranomafana). Moreover, where it can be observed, the altitudinal distributions of the species are wider. In the Marojejy National Park, C. cebegepi sp. nov. was collected from 400 to $700 \mathrm{~m}$ a.s.1., C. jejyorum sp. nov. from 400 to $1200 \mathrm{~m}$ a.s.l. and C. lehibemavo sp. nov. from 400 to $1600 \mathrm{~m}$ a.s.1. In the same area, the six species of Wormaldia were strictly restricted to one altitudinal zone (Gibon 2014, table 1). C. fotobohitra sp. nov. was collected outside the large area of pristine forest, but on a small stream coming from a forest remnant and is possibly a relic species.

Finally, one species is widely distributed, C. fenoevo sp. nov. was collected from the Marojejy in the north to Andohahela in the South, from 70 to $1700 \mathrm{~m}$ a.s.l. It was also recorded from the western slope, on headwaters of the Mangoky, Betsiboka and Tsiribihina Rivers. This geographical exception coincides with a different ecological profile. Present on small tributaries, $C$. fenoevo sp. nov. colonizes also broader rivers, further away from the sources, without, however, being a true potamic species (it has never been captured on true large rivers). Another characteristic of this species, compared with other members of the group, is the vegetation of its capture sites. Precisely, the vegetal landscape of the streams (the terrestrial biome sensu Ross 1963) and not the riparian vegetation. Chimarra fenoevo sp. nov. is the only species of the group that is not associated with the evergreen rainforest. On the eastern slope, it was mainly encountered in the forest transition or in secondary forests; in the Central Highlands, in vestigial or relict gallery forests, above rice field areas.

\section{Discussion}

Species distributions in the lehibemavo group are similar to those described for the other subfamilies, Philopotaminae and Rossinae (Gibon 2013, 2014), very different from that described for the minima group (Gibon 2015). We can assume that the widely distributed Malagasy species of the minima group, morphologically close to their continental relatives, have recently colonized the Island. In comparison, the numerous microendemic species of the $C$. lehibemavo species group possibly belong to a much older fauna. Validation of this hypothesis would require genetic research such as that undertaken by Monaghan et al. (2005), who have demonstrated that the Malagasy fauna of Baetidae (Ephemeroptera) is combining archaic and invasive lineages.

\section{Acknowledgements}

I am grateful to all the participants in the program "Biodiversity and Biotypology of the Malagasy continental waters" and to Gwenaelle Genson for DNA-analysis.

\section{References}

Blahnik R.J. 1998. A revision of the Neotropical species of the genus Chimarra, subgenus Chimarra (Trichoptera: Philopotamidae). Memoirs of the American Entomological Institute 59: 1-318.

Blahnik R.J., Holzenthal R.W. \& Huisman J. 2009. Chimarra of Sabah and Sarawak, northern Borneo (Trichoptera: Philopotamidae). Tijdschrift voor Entomologie 152: 109 -166.

Blahnik R.J., Arefina-Armitage T.I. \& Armitage B.J. 2012. The genus Chimarra Stephens (Trichoptera: Philopotamidae) in Vietnam. Insecta Mundi 0229: 1-25.

Cruaud A., Jabbour-Zahab R., Genson G., Cruaud C., Couloux A., Kjellberg F., van Noort S. \& Rasplus J.Y. 2010. Laying the foundations for a new classification of Agaonidae (Hymenoptera: Chalcidoidea), 
a multilocus phylogenetic approach. Cladistics 26 (4): 359-387. https://doi.org/10.1111/j.1096$\underline{0031.2009 .00291 . \mathrm{x}}$

Elouard J.-M. \& Gibon F.-M. 2001. Biodiversité et Biotypologie des eaux continentales de Madagascar. IRD, Montpellier.

Gibon F.-M. 2000. Biologie de la conservation et singularité des cours d'eau. L'exemple des Philopotamidae malgaches (Insecta, Trichoptera). In: Lourenço W.R. \& Goodman S.M. (eds) Diversité et Endémisme à Madagascar: 319-330. Société de Biogéographie, Paris.

Gibon F.-M. 2013. Une sous-famille caractéristique des forêts humides primaires malgaches: les Rossodinae (Trichoptera, Philopotamidae). Zoosystema 35 (2): 151-174. https://doi.org/10.5252/ $\underline{\mathrm{z} 2013 \mathrm{n} 2 \mathrm{a} 2}$

Gibon F.-M. 2014. Philopotaminae of Madagascar (Trichoptera: Philopotamidae). Annales de la Société Entomologique de France (N.S) 50 (3-4): 382-398. https://doi.org/10.1080/00379271.2014.982027

Gibon F.-M. 2015. The Chimarra minima-group in West Africa and Madagascar (Trichoptera, Philopotamidae). Zoosystema 37 (2): 333-350. https://doi.org/10.5252/z2015n2a3

Gibon F.-M. \& Elouard J.-M. 1996. Etude préliminaire de la distribution des insectes lotiques à Madagascar (exemples des Trichoptères Philopotamidae et Diptères Simuliidae). In: Lourenço W.R. (ed.) Biogéographie de Madagascar: 507-516. ORSTOM, Paris. Available from http://horizon. documentation.ird.fr/exl-doc/pleins textes/pleins textes_6/colloques2/010008490.pdf [accessed 15 Mar. 2017].

Gibon F.-M., Andriambelo P.Z. \& Randriamasimanana D. 1999. A study of the diversity and richness of the Malagasy Trichoptera. In: Chantaramongkol P. \& Malicky H. (eds) Proceedings of the 9th International Symposium on Trichoptera: 123-124. University of Chiang-Maï, Chiang-Maï. Available from http://www.documentation.ird.fr/hor/fdi:010021248 [accessed 15 Mar. 2017].

Goodman S.M. (ed.) 1996. A Floral and Faunal Inventory of the Eastern Slopes of the Réserve Naturelle Intégrale d'Andringitra, Madagascar: with reference to elevational variation. Fieldiana: Zoology (new series) 85: 1-319.

Goodman S.M. (ed.) 1999. A floral and faunal inventory of the réserve naturelle intégrale d'Andohahela, Madagascar: with reference to elevational variation. Fieldiana: Zoology (new series) 94: 1-297.

Goodman S.M. (ed.) 2000. A floral and faunal inventory of the parc national de Marojejy, Madagascar: with reference to elevational variation. Fieldiana: Zoology (new series) 97: 1-286.

Kjer K.M., Zhou X., Frandsen P.B., Thomas J.A. \& Blahnik R.J. 2014. Moving toward species-level phylogeny using ribosomal DNA and CO1 barcodes: an exemple from the diverse caddisfly genus Chimarra (Trichoptera: Philopotamidae). Arthropods Systematics and Phylogeny 72 (3): 345-354.

Monaghan M.T., Gattolliat J.-L., Sartori M., Elouard J.-M., James H., Derleth P., Glaizot O., de Moor F., Vogler A.P. 2005. Trans-oceanic and endemic origins of the small minnow mayflies (Ephemeroptera, Baetidae) of Madagascar. Proceedings of the Royal Society B Biological Sciences 272 (1574): 18291836. https://doi.org/10.1098/rspb.2005.3139

Morse J.C. 2015. Trichoptera World Checklist. Available from http://www.clemson.edu/cafls/ departments/esps/database/trichopt/index.htm [accessed 17 Mar. 2017].

Randriamasimanana D. \& Gibon F.-M. 2001. Etude systématique, habitat et répartition géographique des Setodes (Trichoptera : Leptoceridae) de Madagascar. Annales de Limnologie - International Journal of Limnology 37 (2): 125-141. https://doi.org/10.1051/limn/2001008 
Ratnasingham S. \& Hebert P.D.N. 2007. BOLD: The Barcoding of Life Data System (www.barcodinglife. org). Molecular Ecology Notes 7 (3): 355-364. https://doi.org/10.1111/j.1471-8286.2007.01678.x

Resh V.H. \& Unzicker J.D. 1975. Water quality monitoring and aquatic organisms: the importance of species identification. Journal of the Water Pollution Control Federation 47: 9-19.

Ross H.H. 1956. Evolution and classification of the mountain caddisflies. The University of Illinois Press, Urbana.

Ross H.H. 1963. Stream communities and terrestrial biome. Archiv für Hydrobiologie 59: 235-242.

Wilmé L., Goodman S.M. \& Ganzhorn J.U. 2006. Biogeographic evolution of Madagascar's microendemic biota. Science 312: 1063-1065. https://doi.org/10.1126/science.1122806

Wahlberg E. \& Johanson K.A. 2014. The age, ancestral distribution and radiation of Chimarra (Trichoptera: Philopotamidae) using molecular methods. Molecular Phylogenetics and Evolution 79: 433-442. https://doi.org/10.1016/j.ympev.2014.06.023

Manuscript received: 14 April 2016

Manuscript accepted: 24 August 2016

Published on: 18 May 2017

Topic editor: Gavin Broad

Desk editor: Kristiaan Hoedemakers

Printed versions of all papers are also deposited in the libraries of the institutes that are members of the EJT consortium: Muséum national d'Histoire naturelle, Paris, France; Botanic Garden Meise, Belgium; Royal Museum for Central Africa, Tervuren, Belgium; Natural History Museum, London, United Kingdom; Royal Belgian Institute of Natural Sciences, Brussels, Belgium; Natural History Museum of Denmark, Copenhagen, Denmark; Naturalis Biodiversity Center, Leiden, the Netherlands; Museo Nacional de Ciencias Naturales-CSIC, Madrid, Spain; Real Jardín Botánico de Madrid CSIC, Spain. 